\title{
The Relationship Between the Geniculocortical Afferents and Their Cortical Target Cells During Development of the Cat's Primary Visual Cortex
}

\author{
Carla J. Shatz ${ }^{1}$ and Marla B. Luskin ${ }^{2}$ \\ Department of Neurobiology, Stanford University School of Medicine, Stanford, California 94305
}

To study the prenatal development of connections between the lateral geniculate nucleus (LGN) and the primary visual cortex in the cat, we have examined the relationship between the position of ingrowing afferents from the LGN and their target cells in cortical layers 4 and 6 at various times during the cat's $65 \mathrm{~d}$ gestation period and during the first 3 weeks of postnatal life. In 1 series of experiments, the method of transneuronal transport of intraocularly injected tritiated proline ( ${ }^{3} \mathrm{H}$-proline), followed by autoradiography, was used to label the developing geniculocortical pathway. In another series, the tritiated thymidine ( ${ }^{3} \mathrm{H}$-thymidine) method was employed to keep track of the cells destined for layers 4 and 6 by labeling them on their birthdates (layer 4: embryonic day (E) 37-43; layer 6: E31-36) (Luskin and Shatz, 1985b) and then charting their locations at subsequent times during development. The results of the 2 sets of experiments were compared at corresponding ages.

By E39, many of the cells of cortical layer 6 have completed their migrations and are situated within the cortical plate immediately above the subplate. However, the transneuronal labeling pattern indicates that the geniculocotical afferents have not yet arrived within the vicinity of the future visual cortex, but rather are still en route and confined within the optic radiations of the telencephalon. By E42, a week after the first afferents can be detected in the radiations, substantial transneuronal label is found in the subplate immediately below future visual cortex. However, the overlying cortical plate is free of label. Over the next 2 weeks, geniculocortical axons continue to accumulate in the subplate zone, and, in addition, transneuronal label can be found in the marginal zone. By E55 a faint geniculocortical projection can be detected within the cortical plate, but only within its deeper half (future layers 5 and 6 ), and even then the major portion of the projection is still confined to the subplate. The absence of a projection to cortical layer 4 at these ages is remarkable in view of the results from our ${ }^{3} \mathrm{H}$-thymidine experiments, which indicate that by E57 the majority of cells destined to belong to layer 4 have already completed their migrations and assumed positions superficial to the cells of layers 5 and 6.

By birth, a substantial geniculocortical projection to cortical layer 4 can be detected in the transneuronal autoradiographs.

\footnotetext{
Received Feb. 25, 1986; revised June 30, 1986; accepted July 7, 1986.

We are grateful to Angela DiBerardino and Mark Nakamura for their assistance with histology, Mark Siegel for photographic assistance, and Cecele Thomas for help with word processing. This work was supported by NIH Grants EY 02858 and EY 00248 to C.J.S. and Training Grant NS 07158 to M.B.L.

Correspondence should be addressed to Dr. Carla J. Shatz at the above address.

' Some of this material was presented at Cornell University on September 25 , 1986 , as part of the Rosenblatt lecture series in honor of Dr. Frank Rosenblatt, a deceased member of the Section of Neurobiology and Bchavior.

${ }^{2}$ Present address: Department of Cell Biology, Washington University School of Medicine, St. Louis, MO 63110.

Copyright (C) 1986 Society for Neuroscience $0270-6474 / 86 / 123655-14 \$ 02.00 / 0$
}

The cortex is nevertheless very immature with regard to the organization of its afferent input and the laminar arrangement of its constituent cells. ${ }^{3} \mathrm{H}$-Thymidine studies show that the majority of cells destined for the most superficial cortical layers (layers 2 and 3 ) have not yet completed their pialwards migrations and instead are still en route through the deeper cortical layers. Neurons belonging to layers 2 and 3 do not assume their final positions within the cortex until about 3 weeks postnatal, and it is just at this time that the segregation of the geniculocortical afferents into the system of ocular dominance columns in layer 4 commences (LeVay et al., 1978). These observations indicate that while the geniculocortical afferents arrive within the telencephalon in the vicinity of the visual cortex early in development, they undergo a prolonged period of waiting in the subplate and only invade their target cortical layers once the neurons comprising those layers have completed their migrations and assumed their final relative positions within the cortex.

The development of connections between the thalamus and cortex in the mammalian central nervous systems requires the coordination of many events that are often separated from each other both in time and location. For example, during the development of the visual system, 2 separate sets of neuronsthose of the lateral geniculate nucleus (LGN) and those of the visual cortex - are generated at different times in germinal zones distant from one another, and then migrate independently to their final destinations in the diencephalon or telencephalon. Tritiated thymidine- ( ${ }^{3} \mathrm{H}$-thymidine) labeling studies have shown that, both in cat and monkey, genesis of the neurons of the LGN occurs during the 1 week period immediately preceding genesis of the primary visual cortex (Hickey and Hitchcock, 1984; Rakic, 1977; Shatz, 1981). The neurogenesis of cortex occurs over an extended period of time, with the neurons of the deepest cortical layer generated first and those of the more superficial layers generated thereafter (Luskin and Shatz, 1985b; Rakic, 1974). Consequently, the genesis of the principal target cells of the geniculocortical axons-those of layers 4 and 6-occurs at different times, the neurons of layer 4 being generated substantially later than the LGN neurons that come to supply their input in the adult. These observations raise a number of questions concerning the spatiotemporal relationship between the ingrowing LGN axons and the neurons of cortical layers 4 and 6 during development.

In order to examine this relationship, it is necessary to determine, on the one hand, when the LGN neurons send their axons into the telencephalon and, on the other, when the neurons of layers 4 and 6 complete their migrations from the ventricular zone to their final destinations within the cortical plate. Previous studies in monkey (Rakic, 1977) and rat (Lund and Mustari, 1977) have already shown that axons from the LGN are present in the telencephalon several days after the first layer 
Table 1. ${ }^{3} \mathrm{H}$-Amino acid eye injection protocols

\begin{tabular}{llll}
$\begin{array}{l}\text { Age at } \\
\text { injection }\end{array}$ & $\begin{array}{l}\text { Age at } \\
\text { perfusion }\end{array}$ & \multicolumn{2}{l}{ Amount and volume } \\
\hline E29 & E35 & 100 & $\mu \mathrm{Ci} / 1 \mu \mathrm{l}$ \\
E33 & E39 & 200 & $\mu \mathrm{Ci} / 1.5 \mu \mathrm{l}$ \\
E37 & E42 & 200 & $\mu \mathrm{Ci} / 2.0 \mu \mathrm{l}(\mathrm{RE})$ \\
& & 100 & $\mu \mathrm{Ci} / 1.0 \mu \mathrm{l}(\mathrm{LE})$ \\
E40 & E46 & 200 & $\mu \mathrm{Ci} / 3.0 \mu \mathrm{l}$ \\
E46 & E52 & 250 & $\mu \mathrm{Ci} / 12 \mu \mathrm{l}(\mathrm{RE})$ \\
& & 250 & $\mu \mathrm{Ci} / 12 \mu \mathrm{l}(\mathrm{LE})$ \\
E48 & E55 & 800 & $\mu \mathrm{Ci} / 10 \mu \mathrm{l}$ \\
E49 & E55 & 1.2 & $\mathrm{mCi} / 6 \mu \mathrm{l}$ \\
E51 & E56 & 1.2 & $\mathrm{mCi} / 20 \mu \mathrm{l}$ \\
E52 & E58 & 500 & $\mu \mathrm{Ci} / 15 \mu \mathrm{l}(\mathrm{RE})$ \\
& & 500 & $\mu \mathrm{Ci} / 15 \mu \mathrm{l}(\mathrm{LE})$ \\
E58 & E63 & 1.0 & $\mathrm{mCi} / 20 \mu \mathrm{l}$ \\
E59 & P0 ${ }^{a}$ & 500 & $\mu \mathrm{Ci} / 10 \mu \mathrm{l}$
\end{tabular}

E, embryonic day. RE, right eye. LE, left eye.

${ }^{a}$ This animal was born after $67 \mathrm{~d}$ of gestation, rather than the usual 65.

4 neurons have been generated at the ventricular zone. For instance, in the monkey, the genesis of layer 4 begins around embryonic day 65 (E65), and geniculocortical axons can be detected by E78, at which time the axons have not yet invaded the cortical plate but rather have accumulated below it in the intermediate zone (future white matter). However, in view of the relatively early birthdates of the LGN neurons in every species studied, it is conceivable that many geniculocortical axons could in fact arrive in the intermediate zone many days before layer 4 neurons are even generated.

In the present study we sought to examine these interrelationships in the development of the cat's visual system. To study the time course and pattern of development of the geniculocortical pathway, the method of transneuronal transport of intraocularly injected tritiated proline $\left({ }^{3} \mathrm{H}\right.$-proline) was used, with the earliest injections being made at the time that the first neurons of the LGN were postmigratory (Shatz, 1981; C. J. Shatz and S. J. Eng, unpublished observations). This coincides with the time that retinogeniculate axons would just have reached the anlage of the LGN (Shatz, 1983). In addition, the positions of the cells destined for cortical layers 4 and 6 were charted at various times during fetal and postnatal life using ${ }^{3} \mathrm{H}$-thymidine birthdating. This combined approach permitted us to examine directly the location of the ingrowing geniculocortical afferents with respect to their cortical targets. Our results show that axons from the LGN arrive within the telencephalon at least $2 \mathrm{~d}$ before the first neurons of layer 4 are generated. Moreover, the majority of geniculocortical axons remain in the intermediate zone and do not invade the cortical plate until the cells of layer 4 have migrated to their final destination. A preliminary report of this work has already appeared (Luskin and Shatz, 1984).

\section{Materials and Methods}

Twenty-one cat fetuses of known gestational ages were studied. (See Shatz, 1.983, and Luskin and Shatz, 1985a, for details of the breeding protocols.) Eleven of these received intraocular injections of ${ }^{3} \mathrm{H}$-proline in order to label the retinogeniculocortical pathway at various ages between E29 and E59 by means of the method of transneuronal transport (LeVay et al., 1978; Rakic, 1977; Wiesel et al., 1974). Gestation is 65 $\mathrm{d}$ in the cat. The other 10 fetuses received ${ }^{3} \mathrm{H}$-thymidine at times between E31 and E56 in order to label selectively neurons destined for specific cortical layers, in particular those of layers 4 and 6 (Luskin and Shatz, 1985b). Autoradiographic methods were used to visualize the distri-
Table 2. Amount of ${ }^{3} \mathrm{H}$-thymidine injected at the various fetal and postnatal ages studied

\begin{tabular}{llll}
$\begin{array}{l}\text { Age at } \\
\text { injection }\end{array}$ & $\begin{array}{l}\text { Age at } \\
\text { perfusion }\end{array}$ & $\begin{array}{l}\text { Amount } \\
(\mathrm{mCi})\end{array}$ & $\begin{array}{l}\text { Volume } \\
(\mathrm{ml})\end{array}$ \\
\hline E31 & E47 & 0.5 & 0.05 \\
E33 & P1 & 0.75 & 0.15 \\
E37 & E57 & 0.75 & 0.15 \\
E42 & P0 & 1.0 & 0.1 \\
E42 & P25 & 1.0 & 0.1 \\
E43 & E57 & 1.5 & 0.15 \\
E43 & E58 & i.v. & \\
E43 & P11 & i.v. & \\
E48 & P0 & 2.0 & \\
E56 & P0 & 2.0 & 0.2 \\
\hline
\end{tabular}

${ }^{a}{ }^{3} \mathrm{H}-\mathrm{Thymidine}$ administered intravenously (i.v.) to pregnant mother at $10 \mathrm{mCi} /$ $\mathrm{kg}$.

bution of labeled geniculocortical afferents or cortical cells at appropriate times thereafter.

\section{Surgery and injections}

Timed pregnant cats received an initial intramuscular injection of a mixture of ketamine hydrochloride $(20 \mathrm{mg} / \mathrm{kg})$ and accpromazine $(0.2$ $\mathrm{mg} / \mathrm{kg}$ ). Atropine sulfate $(0.05 \mathrm{mg} / \mathrm{kg})$ was also injected intramuscularly. Anesthesia during surgery was maintained with halothane $(0.5-1.5 \%)$ mixed with nitrous oxide and oxygen (0.3:1.0 liters/min) delivered through an endotracheal tube. Expired $\mathrm{CO}_{2}$ was monitored. An intravenous cannula was inserted to permit the continuous administration of $5 \%$ dextrose in Ringer's solution, and terbutaline sulfate $(0.03 \mathrm{mg} /$ $\mathrm{kg}$ ) when needed to minimize uterine contractions. All surgical procedures were performed in a sterile environment.

The intraocular injections werre made by incising the uterine wall and exposing a fetal head, as described by Shatz (1983). Either unilateral or, in instances where we wished to increase the probability of success, bilateral injections of ${ }^{3} \mathrm{H}$-proline (NET 483, $100 \mathrm{Ci} / \mathrm{mmol}$; New England Nuclear, or TRK $534,80-110 \mathrm{Ci} / \mathrm{mmol}$; Amersham) in $0.9 \%$ sterile saline were made into the vitreous body using a 31 -gauge needle attached to a syringe (Unimetrics Corp., CA). Following the injections, the fetal head was tucked back inside the uterus and all incisions were sutured closed. A postinjection survival time of 5-9 d was chosen to allow adequate time for transneuronal transport to occur, whereupon each animal was prepared for histological processing. A summary of the amount of injected label and survival time for each fetus studied is given in Table 1.

The ${ }^{3} \mathrm{H}$-thymidine injections were made directly through the uterine wall (Hickey et al., 1983) or, in 1 case, by intravenous injection of a pregnant, anesthetised cat. Table 2 lists the quantities of ${ }^{3} \mathrm{H}$-thymidine (NET 027Z, 50-80 Ci/mmol; New England Nuclear) in 0.9\% sterile saline injected and the survival times chosen for each of the fetal ages studied. Further details of this procedure can be found in Luskin and Shatz (1985a, b).

\section{Histology}

Histological methods for the ${ }^{3} \mathrm{H}$-proline- and ${ }^{3} \mathrm{H}$-thymidine-labeled animals were the same. For perfusion, fetuses were removed by cesarean section as described previously, while neonatal cats were perfused following induction of anesthesia with Nembutal $(35 \mathrm{mg} / \mathrm{kg}$ i.p.). Each was perfused transcardially by means of a peristaltic pump with $0.1 \mathrm{M}$ phos-

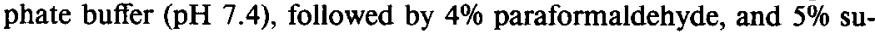
crose in $0.1 \mathrm{M}$ phosphate buffer. The brain was removed and postfixed at $4^{\circ} \mathrm{C}$ in the same fixative to which $20 \%$ sucrose had been added. Next the brain was embedded in a mixture of gelatin and albumin and sectioned on a freezing microtome at $20 \mu \mathrm{m}$ in the coronal plane. The coronal plane of section was selected here in order to facilitate comparisons between ages.

Standard methods were used to process sections for autoradiography (see Luskin and Shatz, 1985a). Adjacent sections were stained for cresyl 

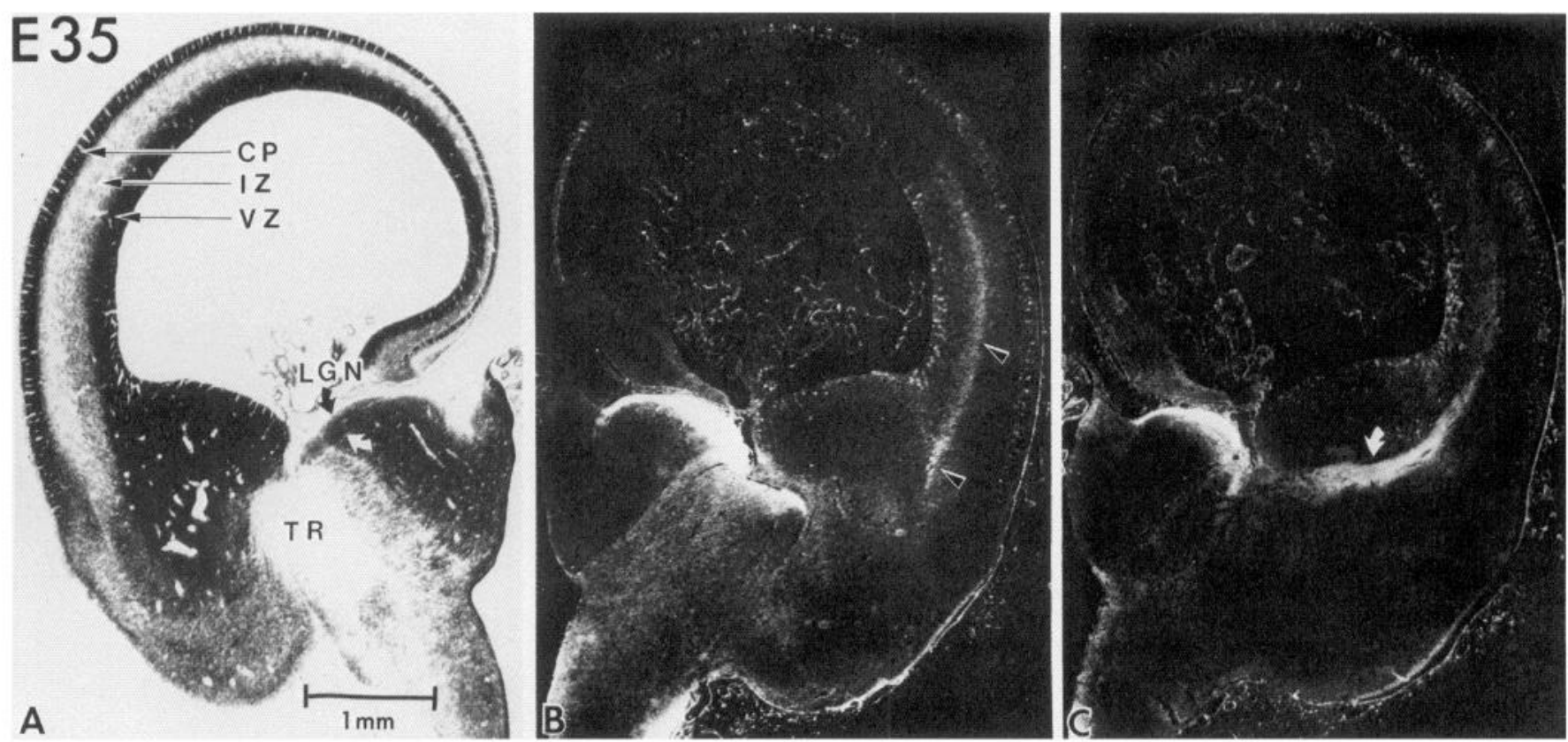

Figure 1. Pattern of autoradiographic labeling in the contralateral diencephalon and telencephalon on E35 resulting from an intraocular injection of ${ }^{3} \mathrm{H}$-proline on E29, illustrated in coronal sections. A, Histological appearance of the brain stained with cresyl violet (in bright-field optics). The pair of curved white and black arrows marks the boundaries of the anlage of the LGN, situated medial and dorsal to the thalamic radiations (TR). The 3 principal embryonic zones of the developing telencephalon are indicated: the ventricular zone $(V Z)$, intermediate zone $(I Z)$, and cortical plate $(C P) . B$ and $C$, Autoradiographs (in dark-field optics) of the distribution of labeled retinogeniculate afferents to the LGN, and transneuronally transported label in the optic radiations ( $B$, arrowheads). $B$ and $A$ are immediately adjacent. $C$ is taken from a more anterior level and shows the transneuronally labeled fibers of the internal capsule as they condense to form the thalamic radiations (curved arrow). Note that the transneuronally labeled geniculocortical projection approaches, but does not enter, the dorsal and medial parts of the telencephalon (presumptive visual cortex) at this early age. Orientation: dorsal is up. Calibration bar applies to $A-C$.

violet to reveal cytoarchitectonic features. The resulting distribution of radioactive labeling was examined using bright-field and dark-field illumination. Heavily ${ }^{3} \mathrm{H}$-thymidine-labeled cells can be easily identified by the accumulation of clusters of silver grains over their nuclei. A cell was judged to be heavily labeled, and thus born at the time of ${ }^{3} \mathrm{H}-$ thymidine administration, if the number of silver grains over its nucleus was equal to or greater than half the maximum number of silver grains found over the nucleus of the most heavily labeled cells in that particular case. (Cells that have undergone additional divisions after incorporating ${ }^{3} \mathrm{H}$-thymidine will appear lightly labeled owing to the dilution of the label.) In practice, it is relatively simple to distinguish heavily and lightly labeled cells from one other by inspection, thus eliminating the need for counting the silver grains overlying every cell.

It is difficult to identify the border between areas 17 and 18 in the fetal brain on the basis of conventional cytoarchitectonic criteria. Therefore, for our analysis the primary visual cortex in the fetal brain was assumed to occupy the same relative position in the developing brain that it does in the adult. (See Luskin and Shatz, 1985a, for a more complete discussion of this point.) Consequently, we designated the cortex located along the medial bank of the lateral gyrus from its apex ventralward to the first sulcus (presumptive splenial sulcus) as the future primary visual cortex. The pattern of transneuronal labeling observed in this study supported this designation (see Results).

\section{Results}

\section{Development of the geniculocortical projection}

The earliest age at which intraocular injections of ${ }^{3} \mathrm{H}$-proline were made for transneuronal transport was E29. This age was selected for 2 reasons. First, previous ${ }^{3} \mathrm{H}$-thymidine studies in the cat have shown that the neurons of the LGN are generated between E24 and E31 (Hickey and Hitchcock, 1984; Shatz, 1981), and that by E29 the first-generated neurons have just completed their migrations and collected to form the anlage of the LGN (C. J. Shatz and S. J. Eng, unpublished observations).
Second, the first axons of the retinogeniculate projection can just be detected in the vicinity of the LGN anlage (Shatz, 1983). Consequently, E29 is the earliest age at which the transneuronal transfer of radioactive label might be expected to work.

Figure 1 shows the results of an experiment in which a fetus received an intraocular injection of ${ }^{3} \mathrm{H}$-proline at E29 and was removed for study at E35. At this age the LGN is a thin accumulation of cells located at the dorsolateral margin of the diencephalon (Fig. 1A). The telencephalon consists of 3 major embryonic zones, which can be seen in the cresyl violet-stained section of Figure $1 A$ : the ventricular zone (VZ, the site of neurogenesis), the intermediate zone (IZ, the future white matter), and the cortical plate $(\mathrm{CP}$, the destination of migrating, postmitotic neurons of the future cortex). Even by this early age, axons of LGN neurons have already joined the thalamic radiations and entered the telencephalon. This projection can be seen in the dark-field autoradiographs of Figure $1, B$ and $C$. Radioactive label is present not only in the LGN, but also transneuronally in the internal capsule as the geniculocortical axons condense to form the thalamic radiations (see Fig. 1C). Slightly more posterior, label is present in the optic radiations as a discrete band within the intermediate zone (Fig. $1 B$, arrowheads). These observations demonstrate that by E35 a definite projection from the LGN into the telencephalon has formed. However, the projection is very immature in that it cannot be detected in the vicinity of presumptive visual cortex (e.g., posterior and medial regions of the telencephalon).

By contrast, just 1 week later, at E42, the pattern of transneuronal labeling indicates that the geniculocortical projection has now extended into the posterior and medial regions of the telencephalon - the vicinity of presumptive visual cortex. Figure 2 shows the autoradiographic labeling pattern in the telencephalon at E42, the result of an eye injection made $5 \mathrm{~d}$ earlier. As 

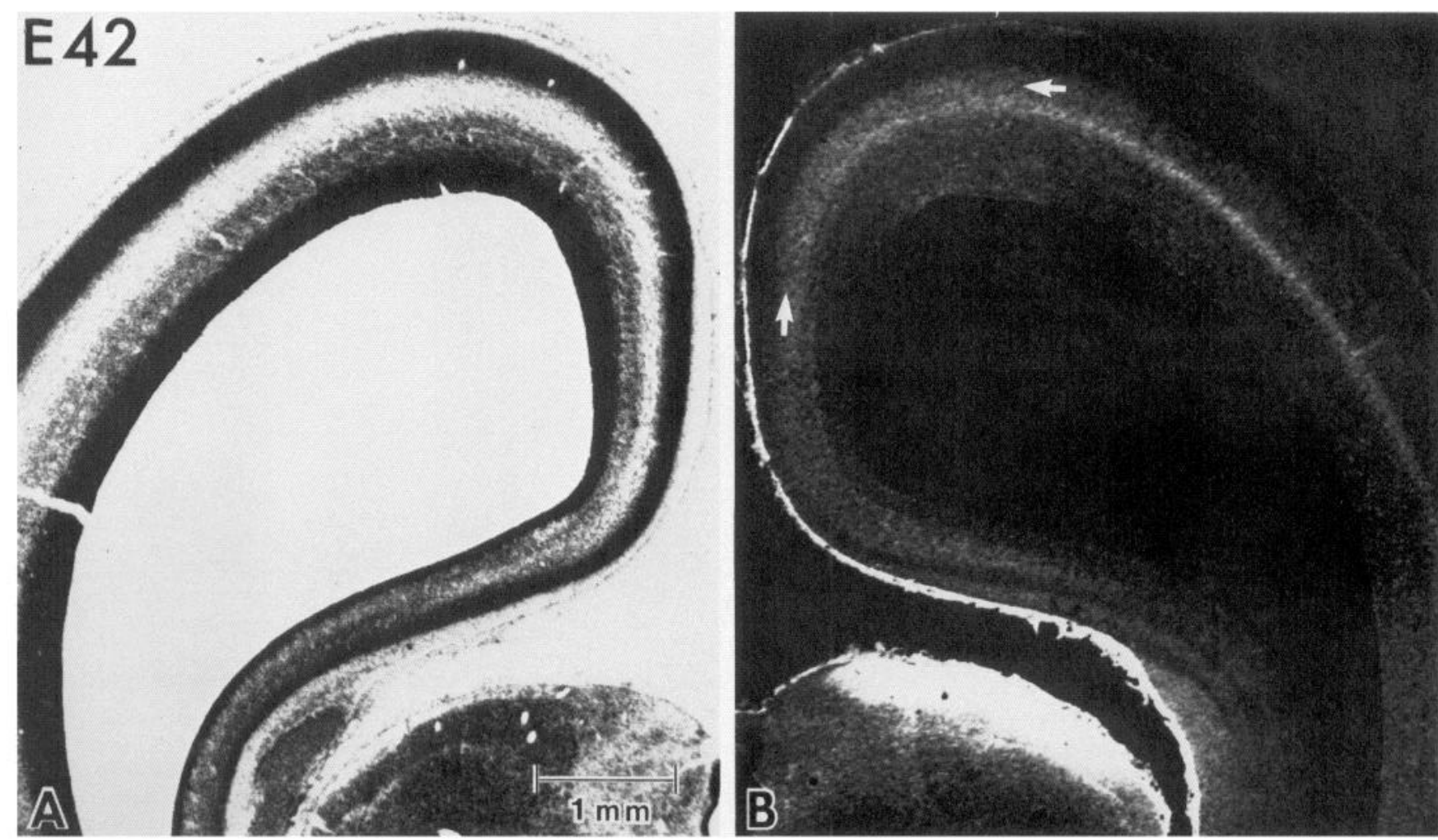

Figure 2. Pattern of transneuronal labeling in the telencephalon on E42 resulting from an intraocular injection of ${ }^{3} \mathrm{H}-$ proline on E37. $A$ and $B$, Adjacent coronal sections. A, Histological appearance of the telencephalon in the vicinity of presumptive visual cortex shown in a section stained with cresyl violet. $B$, Dark-field autoradiograph showing that transneuronally labeled geniculocortical afferents form a discrete band (the optic radiations) that runs in the intermediate zone. In the region of the presumptive visual cortex (dorsal and medial telencephalon) label is also present immediately below the cortical plate in the subplate zones (between arrows). See Figure 4 for nomenclature. Note absence of label in overlying cortical plate. The retinal projection to pretectum is visible below. Bright white band of labeling along medial edge of telencephalon is in pia and is probably associated with leakage of label from pretectum and tectum. Orientation: dorsal is up and lateral is towards the edge of each panel. Calibration bar in $A$ also applies to $B$.

before, in lateral regions of the intermediate zone of the telencephalon, label is confined within the optic radiations as a discrete band. However, below the presumptive visual cortex, label is present not only in the radiations, but in a portion of the intermediate zone sandwiched between the optic radiations and the base of the cortical plate (cf. Fig. 2, $A$ and $B$ ). This zone is known as the subplate, and its location is delineated in the cresyl violet-stained section of Figure $4 A$ (see also Luskin and Shatz, 1985a, Fig. 7, for further definitions). The presence of transneuronally transported label could not be detected within the subplate of another animal that was studied at E39, indicating that this feature of the development of the geniculocortical pathway only emerges thereafter.

The pattern of transneuronal labeling within the telencephalon at E46 is essentially unchanged from that seen just $4 \mathrm{~d}$ earlier, on E42. Again, label is present both within the optic radiations and also within the subplate subjacent to future visual cortex (Fig. 3). In addition, when autoradiographs were examined at high magnification, faint label (above the background normally associated with the pia) was found in the marginal zone (future layer 1).

By E55, the presence of label within both subplate and marginal zones is more evident, perhaps owing to the continued addition of geniculocortical axons to the projection. This pattern of labeling is shown in Figure $4 B$, in which the subplate and marginal zone labeling is most prominent just above (dorsal to) the emerging splenial sulcus. For the first time, faint label can also be detected within the deeper part of the cortical plate in the region of layers 5 and 6 (see the next section and Figs. 7 and 8). Label is again most evident near the splenial sulcus. It is worth noting that even by E52 (not shown), the majority of label is still concentrated within the subplate, indicating that appreciable numbers of geniculocortical afferents do not invade the cortical plate until some time after E52.

Substantial label is present within the cortical plate by birth, but its distribution is far from adultlike in several respects. In the adult visual cortex, the geniculocortical projection is concentrated principally in layers 4 and 6 and the superficial part of layer 1 , with the white matter virtually free of label everywhere except within the optic radiations (LeVay and Gilbert, 1976; Shatz et al., 1977). In contrast, in a fetus injected at E59 and examined at birth, the radial distribution of transneuronal label is almost continuous across the cortical plate. As shown in Figure 5, label extends from the subplate to the pial surface, with the exception of a label-free strip just below the marginal zone. At first glance, it seems that the geniculocortical projection extends pialward far beyond future layer 4 , but results from the ${ }^{3} \mathrm{H}$-thymidine experiments described in the next section (see Figs. 8 and 9) show that, at birth, neurons belonging to the upper border of layer 4 are in fact located closer to the pial surface than they are in the adult. Hence, the transneuronal label coincides with the upper border of layer 4 .

Another obvious difference between the distribution in the cortex of transneuronal label at birth and in the adult is in the tangential dimension. In the adult, a unilateral eye injection produces the patchy labeling within layer 4 characteristic of ocular dominance columns (Shatz et al., 1977). At birth, on the other hand, the columnar organization is absent and does not 

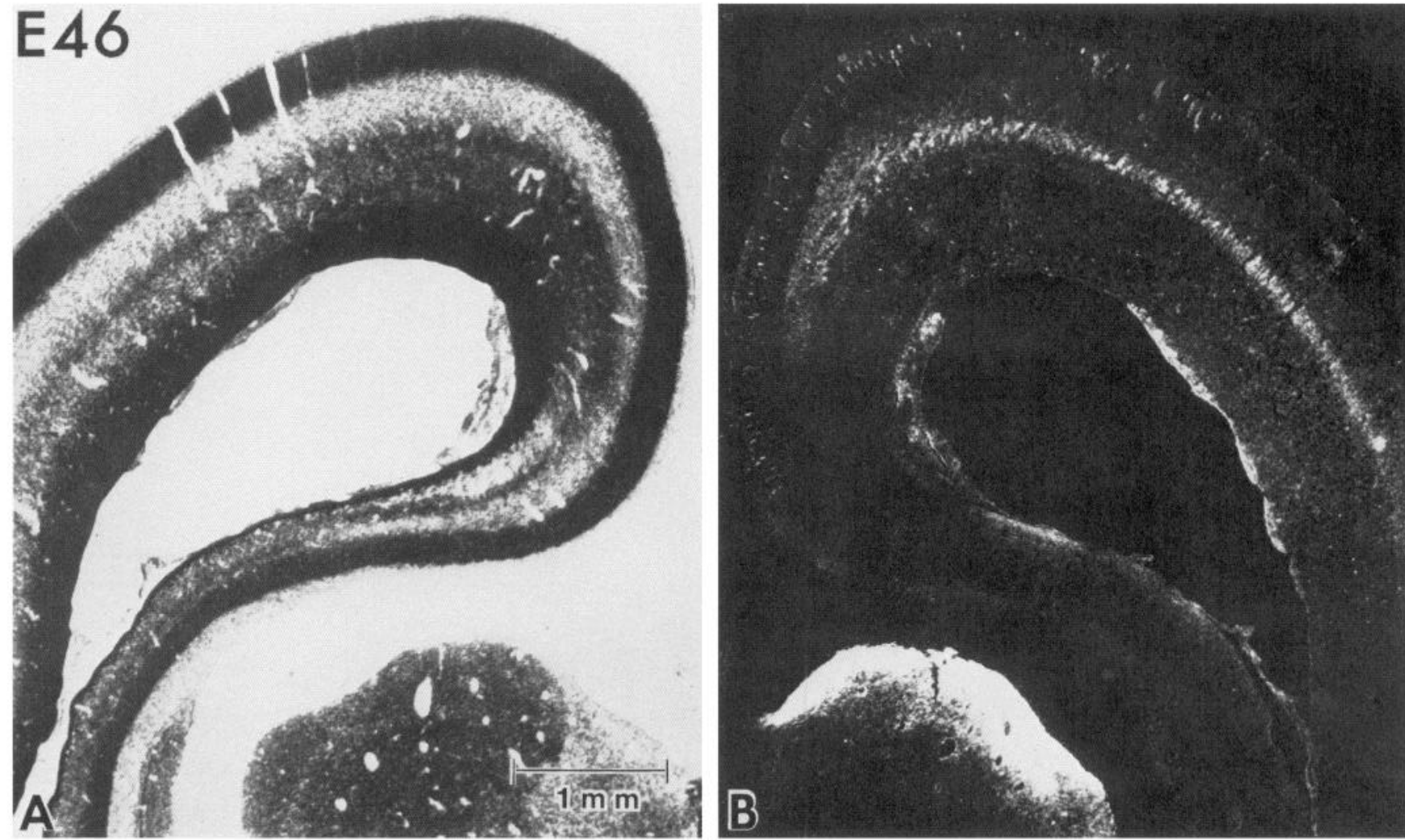

Figure 3. Pattern of transneuronal labeling in the contralateral hemisphere on E46 resulting from an intraocular injection of ${ }^{3} \mathrm{H}$-proline on E40. ( $A$ and $B$ are adjacent coronal sections.) $A$, Cresyl violet-stained section of the telencephalon. $B$, Dark-field autoradiograph showing transneuronally labled geniculocortical afferents in the optic radiations and subplate. Note the absence of label in the cortical plate. At higher magnification (not shown), faint label could also be seen in the marginal zone. Orientation: dorsal up and lateral towards the edge of each panel.

begin to emerge until about 3 weeks postnatal (LeVay et al., 1978). Inspection of Figure 5 also indicates that the density of labeling is not uniform across area 17: Regions at the apex of the lateral gyrus (where central retina is represented) are rela- tively lightly labeled, whereas flanking regions are more heavily labeled. This nonuniformity probably occured because of the uneven uptake of label within the central retina, since the density of label within corresponding regions of the LGN was also low.
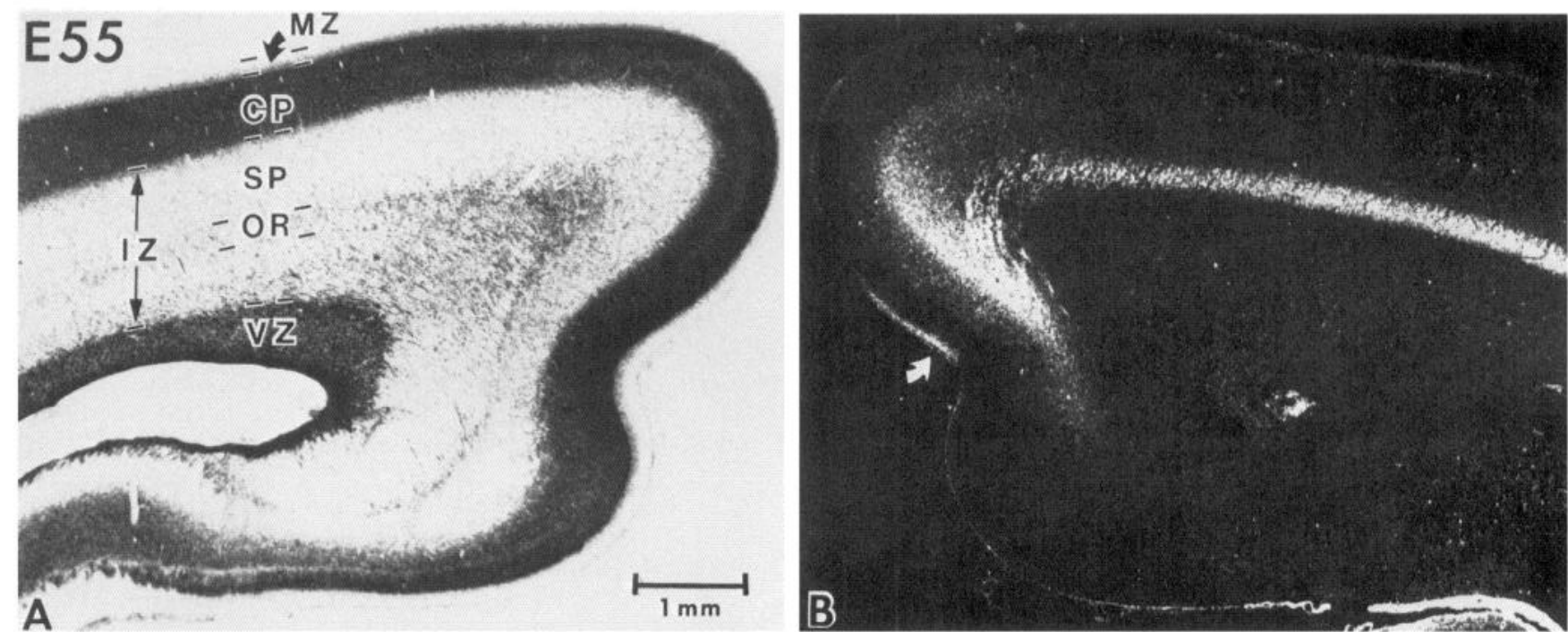

Figure 4. Pattern of transneuronal labeling in the contralateral hemisphere on E55 resulting from an intraocular injection of ${ }^{3} \mathrm{H}-$ proline on E49. $A$, Histological appearance of a cresyl violet-stained section. Embryonic zones of the developing telencephalon are marked: ventricular zone ( $V Z$ ), intermediate zone $(I Z)$, subplate $(S P)$, cortical plate $(C P)$, and marginal zone $(M Z) . B$, Transneuronally labeled geniculocortical afferents shown in dark-field in the adjacent section. Note faint label in the lower half of the cortical plate in the vicinity of the presumptive visual cortex, just above heavy label in the underlying subplate zone. There is also heavy label in the optic radiations $(O R)$ and in the marginal zone just dorsal to the splenial sulcus (curved arrow). Orientation: dorsal is up and lateral is towards the edge of each panel. 

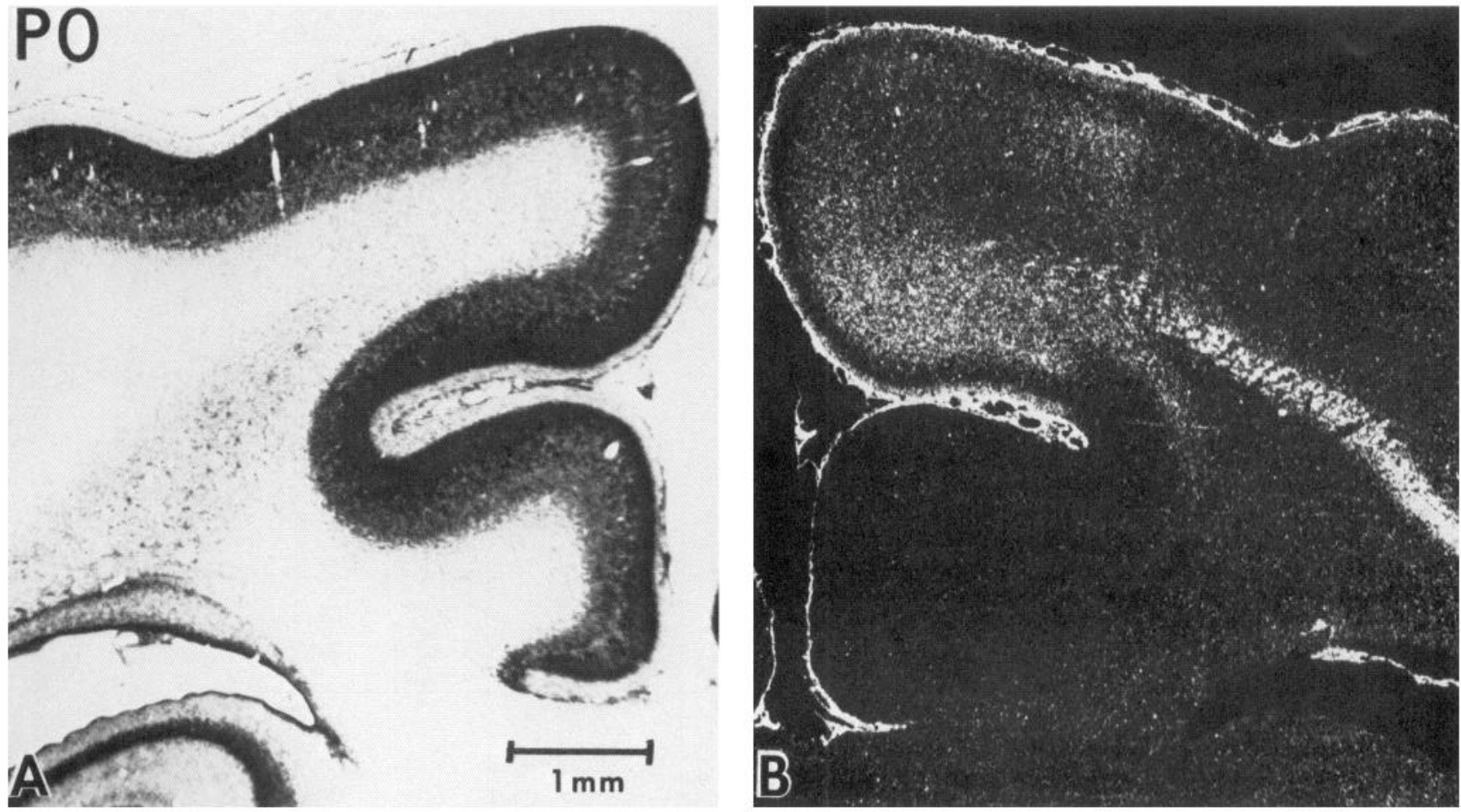

Figure 5. Pattern of transneuronal labeling in the contralateral cortex at birth $(P 0)$ resulting from an intraocular injection of ${ }^{3} \mathrm{H}$-proline on E59. $A$, Cresyl violet-stained coronal section through the region of the primary visual cortex. $B$, Dark-field autoradiograph of an adjacent section. Laterally in $B$, transneuronal label is confined to the optic radiations. In the presumptive visual cortex, however, substantial label is present throughout the cortical plate except in a thin superficial band just below the marginal zone. The marginal zone itself is heavily labeled just below the pial surface.

However, other possibilities, including the delayed ingrowth of geniculocortical afferents representing the central retina, or a difference in magnification factor, could also contribute to this pattern of labeling (see LeVay et al., 1978, p. 228).

Together, the results of the transneuronal transport experiments described above indicate that during the period between E35 and postnatal day (P) 0 , the geniculocortical projection is elaborated. The sequence of events, summarized in Figure 6, begins with the formation of optic radiations within the intermediate zone of the telencephalon by E35, followed by the arrival of the axons within the vicinity of the future visual cortex by E39. Throughout the next 3 weeks, axons accumulate in the subplate zone, but it is not until birth that an appreciable invasion of the cortical plate takes place. Finally, by 3 weeks postnatal the adultlike laminar pattern of geniculocortical input to layers 4 and 6 can be discerned and the segregation of afferents according to eye input commences (LeVay et al., 1978).

\section{Formation of cortical layers 4 and 6}

The finding, described above, that axons from the LGN collect in the subplate during the 4 weeks before birth prompted us to determine where their targets-the cells of cortical layers 4 and 6 -are located during this developmental period. To do this, we used ${ }^{3} \mathrm{H}$-thymidine autoradiography to label the neurons of layers 4 or 6 on their birthdates. In a previous study of the neurogenesis of the cat's visual cortex, we found that the majority of neurons destined for layer 6 are generated between E31 and E36, while those belonging to layer 4 are generated between E37 and E43 (Luskin and Shatz, 1985b). This information allowed us to follow the position of cells destined for different layers at various times during development by tagging them with ${ }^{3} \mathrm{H}$-thymidine on their birthdates and then examining their distributions autoradiographically at subsequent times. In so doing, we found that many of the first-generated cells of layer 6 complete their migrations and arrive at the cortical plate as early as E39, where they reside immediately above the subplate zone (Luskin and Shatz, 1985a). Nevertheless, despite the nearby presence of these postmigratory targets, we have found here that the geniculocortical afferents remain in the underlying subplate for an additional 2 weeks (until about E55) before their growth into the cortical plate can be detected.

A similar approach was used to examine the temporal pattern of migration of the neurons destined for cortical layer 4 . Because of the inside-first, outside-last pattern of cortical neurogenesis, those neurons generated at E37, at the beginning of the neurogenetic period for layer 4 , will ultimately reside at the base of the cortical layer, while those labeled at the end, near E43, will reside at the top of layer 4 . Consequently, ${ }^{3} \mathrm{H}$-thymidine injections were made at either E37 or E43, and the resulting distribution of labeled cells was examined at E57. This end point was chosen because we were particularly interested in knowing the positions of neurons destined for cortical layer 4 at a time when geniculocortical afferents are just beginning to move from the subplate into the deepest part of the cortical plate (see Fig. 4).

The results of such an experiment are shown in Figure 7. When the cortex was examined at E57, following a ${ }^{3} \mathrm{H}$-thymidine injection on either E37 or E43, 2 distinct bands of heavily labeled cells were found. By comparing the distribution of labeled cells in the dark-field autoradiograph of Figure $7 A$ with that in the bright-field photograph of a comparable section stained for cresyl violet (Fig. $7 B$ ), it can be seen that labeled cells resulting from the E37 injection are situated in the middle of the cortical plate, thereby defining the border between the base of layer 4 and the top of layer 5 . A similar comparison for the E43 injection (Fig. $7 C$ ) reveals that at E57 the majority of cells destined to 


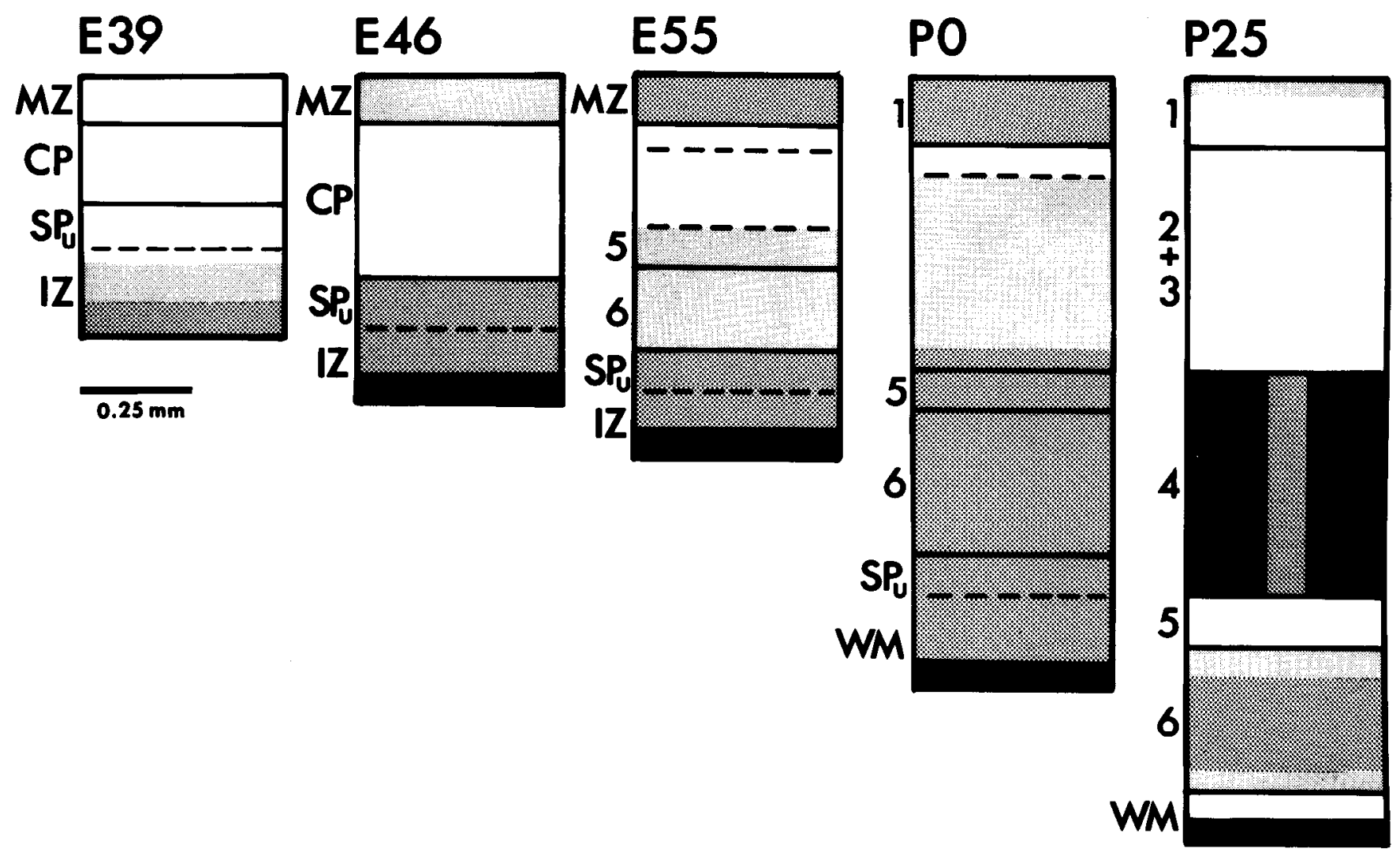

Figure 6. Summary diagram based on camera lucida drawings of autoradiographs depicting the sequential ingrowth of geniculocortical afferents into the visual cortex. At each age, white areas represent locations where no transneuronally transported label above background was detected; black areas indicate regions where the density of label was highest. Dark and light shading represents intermediate levels of labeling. Black bands at the base of each panel (except E39) represent dense labeling found within the optic radiations. By E39, geniculocortical afferents can first be detected in the vicinity of the presumptive visual cortex, where they are largely restricted to the optic radiations of the intermediate zone. By E46, afferents have begun to collect at the top of the intermediate zone (IZ) in the upper part of the subplate ( $\left.S P_{u}\right)$, but are apparently excluded from the overlying cortical plate $(C P)$; faint label is also found in the marginal zone $(M Z)$. By E55, afferents can also be detected in the lower half of the cortical plate (layers 5 and 6 ), but the subplate and marginal zones are still more heavily labeled. By birth (PO), geniculocortical afferents have invaded most of the cortical plate with the exception of a thin band just below the marginal zonc. The decper cortical layers and subplate are still more heavily labeled. Between birth and P25, the adultlike laminar pattern of the geniculocortical projection emerges as the labeling density diminishes within the white matter and layer 5; the system of ocular dominance columns within layer 4 also begins to form. $I Z$, intermediate zone; $S P_{u}$, upper half of subplate (see Luskin and Shatz, 1985a, for details); $C P$, cortical plate; $M Z$, marginal zone. At E55 and P0, layers 5 and 6 can be identified histologically and from ${ }^{3} \mathrm{H}$-thymidine studies (see text); these occupy the lower half of the cortical plate.

belong to the upper half of layer 4 are located at the very top of the cortical plate, just below the marginal zone in a compact zone of high cell density (Fig. $7 B$, asterisk). The relative scarcity of labeled cells other than in the superficial part of the cortical plate indicates that the vast majority of layer 4 cells have completed their outward migrations by E57. Taken together, these results demonstrate that the neurons of layer 4 occupy the entire upper half of the cortical plate at this age.

While the majority of layer 4 neurons have completed their outward migrations and assumed a final position within the upper half of the developing cortical plate at E57, the geniculocortical afferents cannot be detected within this region. This point can be reinforced by directly comparing the pattern of transneuronally transported label at E55 resulting from an earlier eye injection with the pattern of cell labeling resulting at E57 from the administration of ${ }^{3} \mathrm{H}$-thymidine at E37 or E43, as illustrated in Figure 8 . To construct this figure, separate camera lucida drawings of the distribution of heavily ${ }^{3} \mathrm{H}$-thymidinelabeled cells or transneuronally labeled afferents were made using dark-field optics. In each case the relevant laminar borders and zones were identified by inspecting in bright-field optics the same section stained with cresyl violet. Then the distributions of labeled cells were superimposed on a single drawing that could be matched with the pattern of afferent labeling simply by aligning laminar boundaries.

Inspection of Figure 8 indicates that the layer 4 neurons and the geniculocortical afferents occupy separate, nonoverlapping zones within the future visual cortex at E57. The telencephalon at this age consists of several distinct zones based on histological criteria and the results of ${ }^{3} \mathrm{H}$-thymidine autoradiographic studics (Fig. 7, and Luskin and Shatz, 1985a). Besides the cortical plate, there is the overlying marginal zone (MZ) and a subjacent subplate that can be subdivided into an upper $\left(\mathrm{SP}_{\mathrm{u}}\right)$ and lower part. (Formally, the subplate is the upper part of the intermediate zone; see Luskin and Shatz, 1985a, for further definitions.) Thus, ${ }^{3} \mathrm{H}$-thymidine-labeled cells are mainly situated in the upper half of the cortical plate, while the geniculocortical afferents are largely confined to the marginal and subplate zones, with a light projection into the lower half of the cortical plate as well.

Since we knew that, by birth, the geniculocortical projection had not only invaded the deeper part of the cortical plate, but had penetrated into the more superficial regions (see Figs. 5 and 6 ), we wished to determine whether the geniculocortical afferents had finally arrived within the vicinity of their target cells in layer 4. To address this question it was again necessary to use the ${ }^{3} \mathrm{H}$ thymidine method of birthdating to determine the location of 

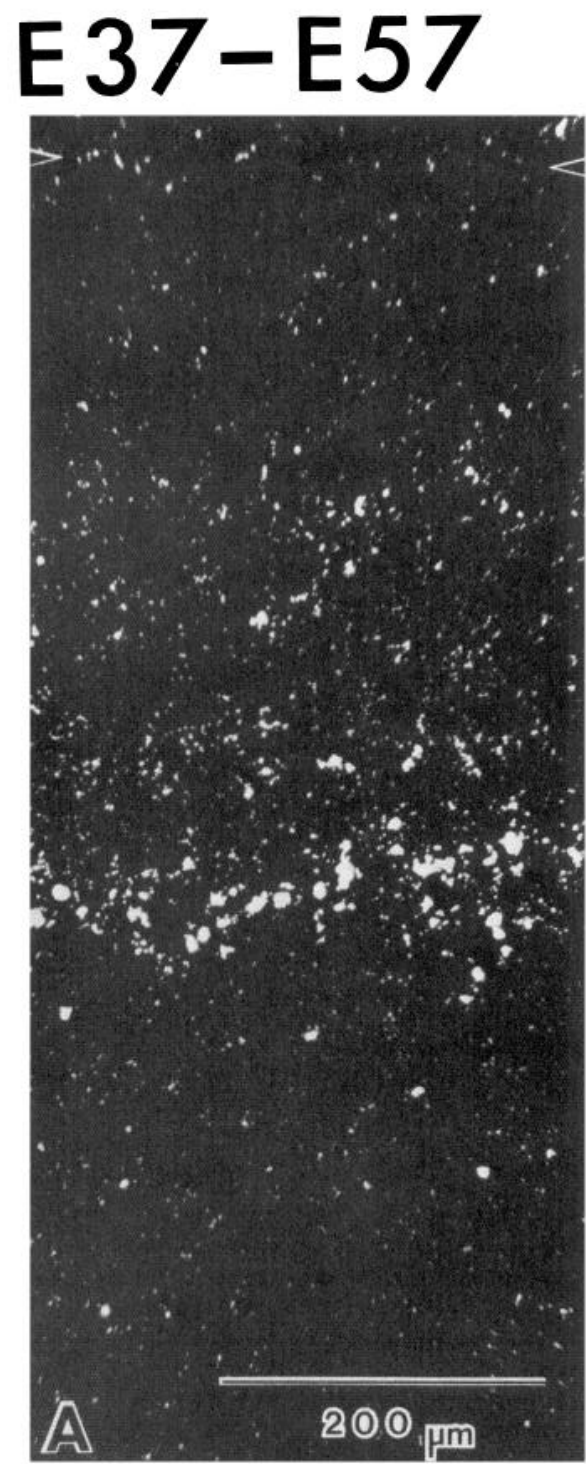

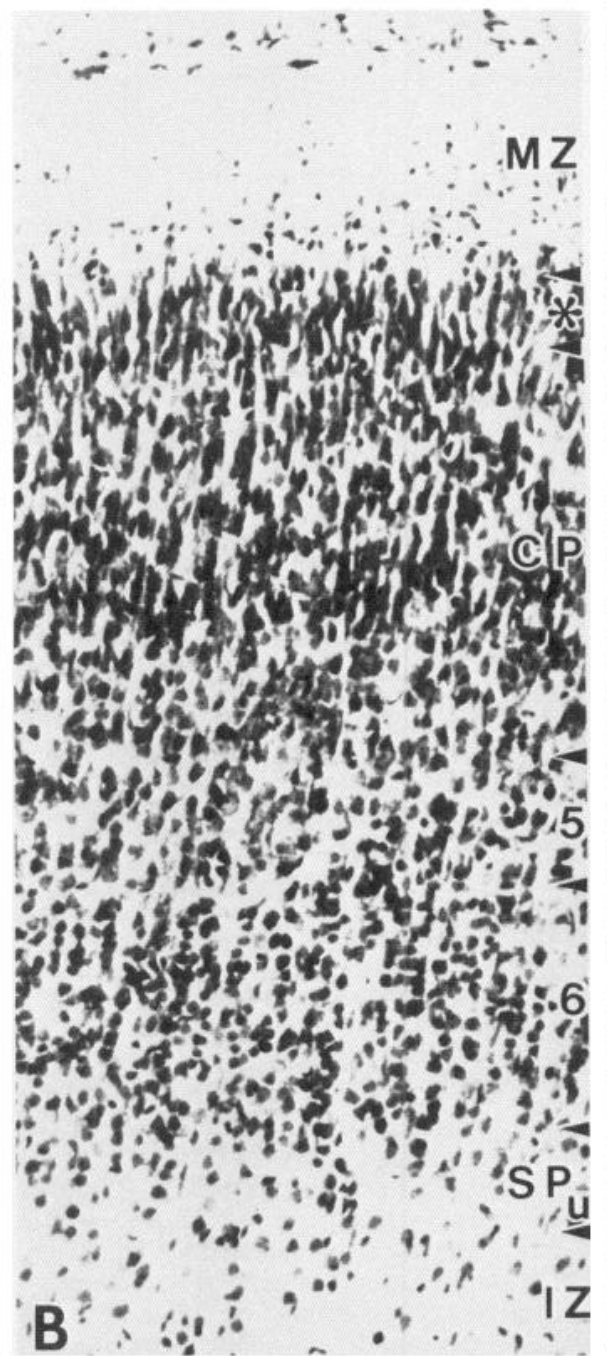

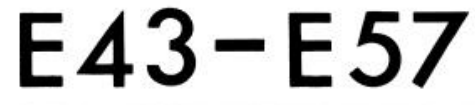

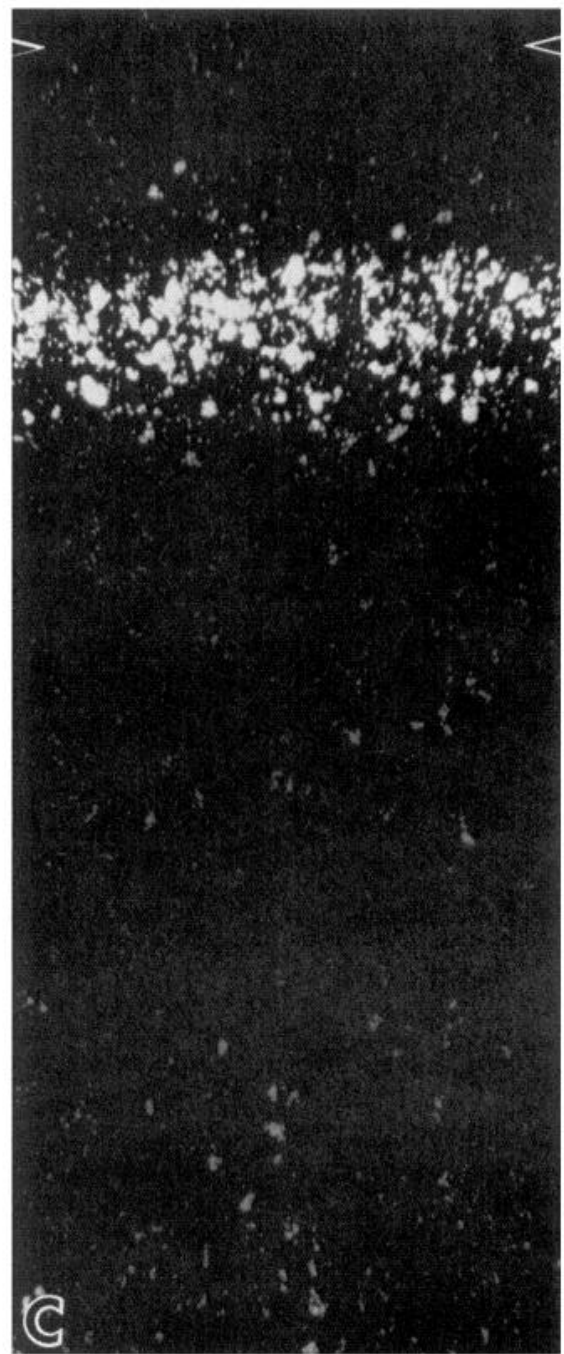

Figure 7. Positions at E57 of neurons destined for cortical layer 4, demonstrated as a result of ${ }^{3} \mathrm{H}$-thymidine injections on their birth dates. $A$ and $C$, Dark-field autoradiographs of ${ }^{3} \mathrm{H}$-thymidine-labeled cells in the presumptive visual cortex, resulting from injections on E37 $(A)$ or E43 $(C)$ to label the cells destined for the lower $(A)$ or upper $(C)$ parts of layer 4 . $B$, Cresyl violet-stained section illustrating the histological composition of the cortex at E57. Layers 5 and 6 of the cortical plate $(C P)$ can be identified, as well as the underlying subplate $\left(S P_{u}\right)$, marginal zone $(M Z)$ and intermediate zone (IZ). The asterisk denotes the compact, densely stained band of cells at the top of the cortical plate. Note that ${ }^{3} \mathrm{H}$-thymidine given on E37 results in a band of labeled cells in the middle of the cortical plate $(A)$, whereas ${ }^{3} \mathrm{H}$-thymidine given on E43 $(C)$ results in a band of labeled cells situated within the compact zone at the top of the cortical plate. Calibration bar in $A$ applies to $B$ and $C$.

Figure 8. Summary diagram of the relationship between the location of the geniculocortical afferents and that of the cells destined to belong to the upper and lower parts of layer 4 at E57. Left-hand panel illustrates superimposed camera lucida drawings of the distribution of heavily labeled cells in the cortex at E57 resulting from the injection of ${ }^{3} \mathrm{H}$ thymidine on E37 (black dots) or E43 (asterisks). Note that the cells destined for layer 4 occupy the entire upper half of the cortical plate on E57. The camera lucida drawing on the right summarizes the pattern and relative density of transneuronally labeled geniculocortical afferents at E55 (see Fig. 6). Although the upper part of the cortical plate contains many layer 4 neurons, the geniculocortical afferents cannot be detected there at this age. $M Z$, Marginal zone; $I Z$, intermediate zone; $S P_{u}$, upper portion of subplate zone.
E57 Cells

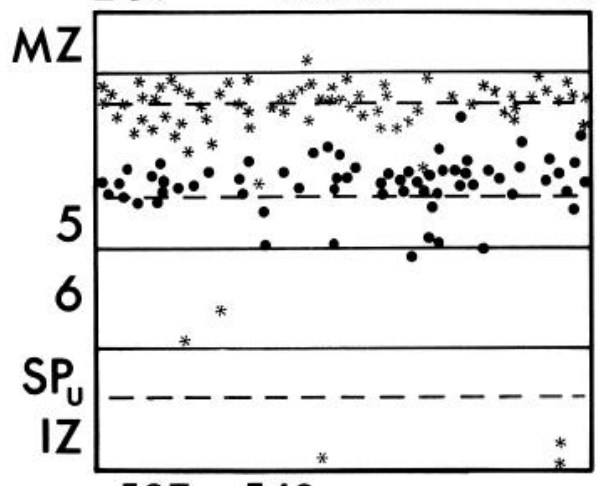

- E37*E43
E55 Afferents

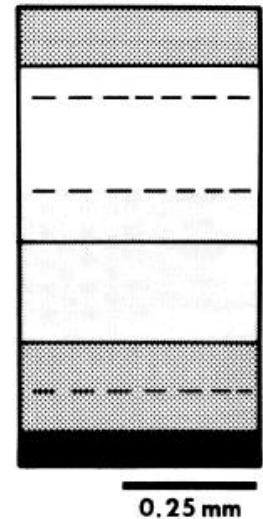




\section{E42-P0}

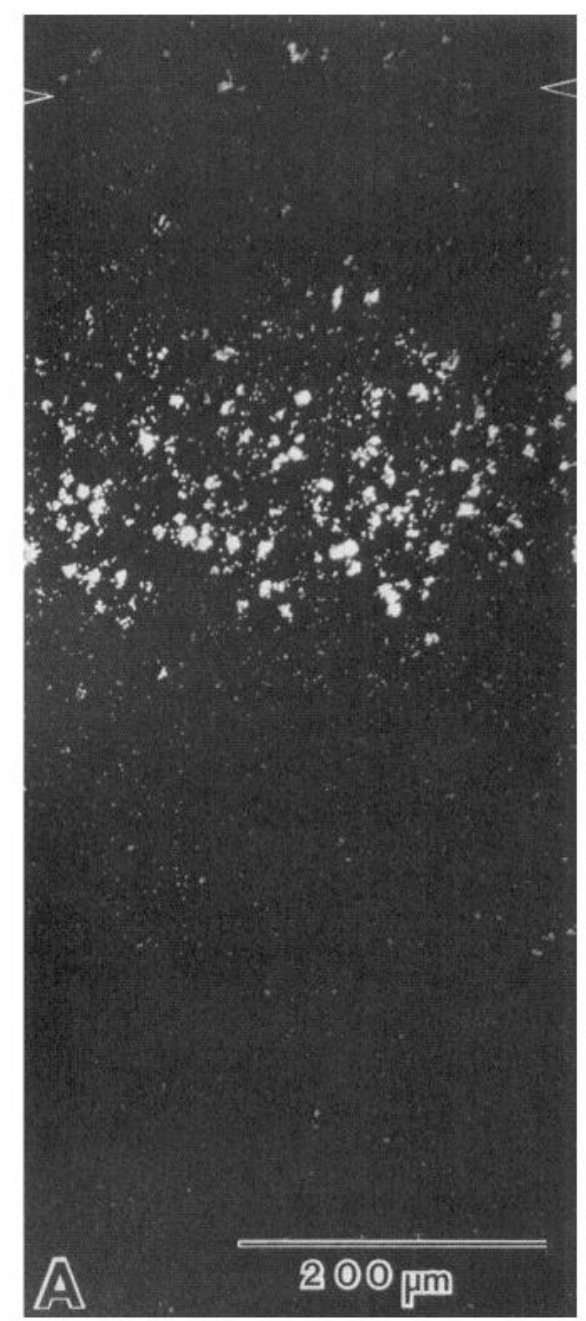

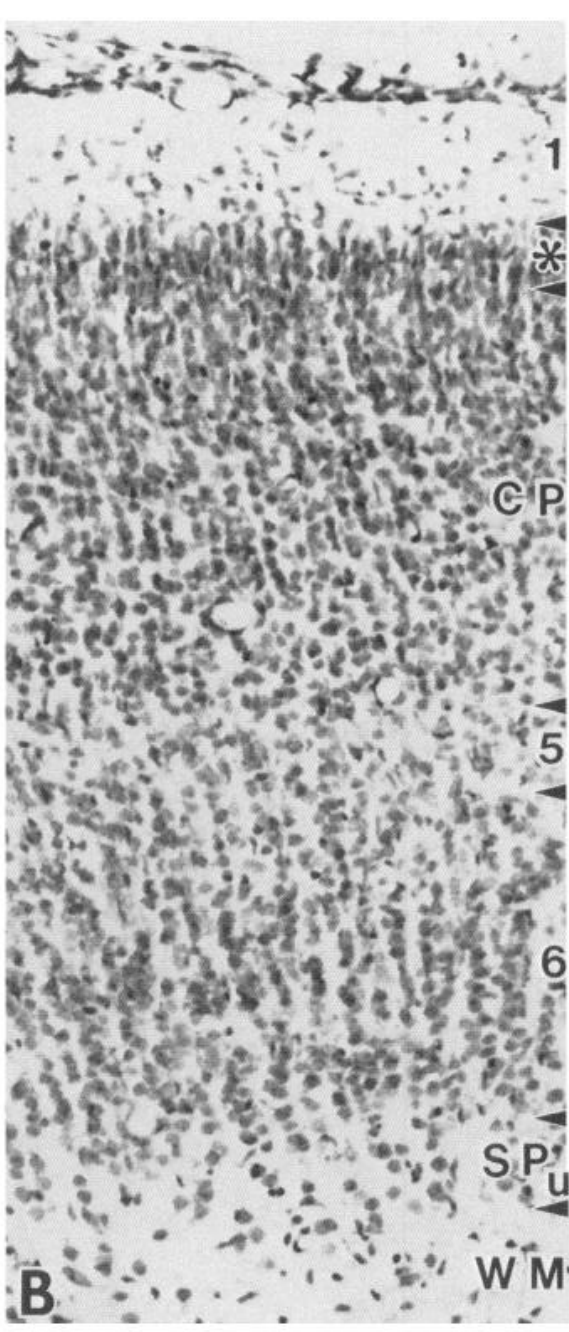

\section{E48-P0}

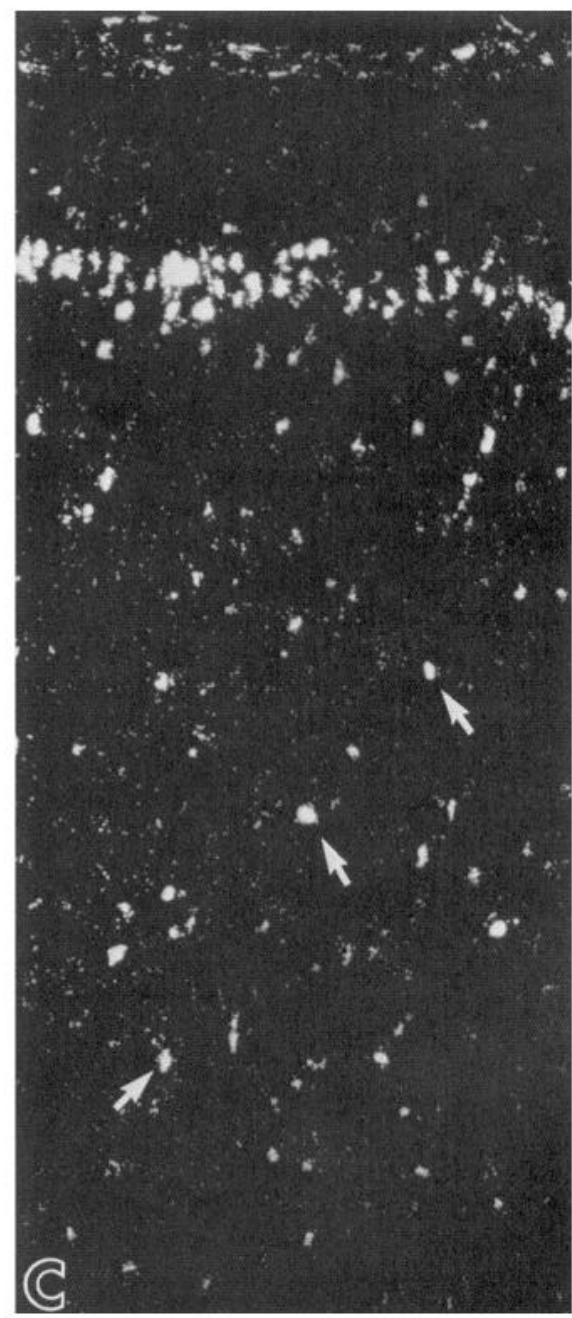

Figure 9. The positions at birth of neurons destined for the upper part of layer 4 and the more superficial cortical layers demonstrated by ${ }^{3} \mathrm{H}$ thymidine labeling. $A$ and $C$, Dark-field autoradiographs of ${ }^{3} \mathrm{H}$-thymidine-labeled cells at birth $(P 0)$ resulting from an injection on either E42 $(A)$ to label the cells destined for the layer $3 / 4$ border, or E48 $(C)$, to label the cells destined for the superifical cortical layers (layers 2 and 3). $B$, Cresyl violet-stained section illustrating the histological composition of the cortex at birth. $A,{ }^{3} \mathrm{H}$-thymidine given on $\mathrm{E} 42$ results at birth in a band of labeled cells situated close to the top of the cortical plate. $C,{ }^{3} \mathrm{H}$-thymidine given on E48 results in a band of labeled cells within the compact zone at the top of the cortical plate. Many heavily labeled cells are also found at varying depths in the cortical plate (arrows) at P0. Thus the organization of the superficial half of the cortex is extremely immature at birth. Calibration bar in $A$ also applies to $B$ and $C$. Arrowheads subdivide cortex by layer in bright-field picture $(B): W M$, white matter; $S P_{u}$, upper half of subplate; asterisk, compact zone of cells at top of cortical plate; $C P$, upper portions of cortex that cannot yet be identified by layer histologically.

the cells of layer 4 within the neonatal cortex. This approach was required because it is not possible to infer the position of each cortical layer at this age from a simple inspection of cresyl violet-stained sections; as demonstrated below, neurons destined for the superficial cortical layers (layers 2 and 3) have not completed their migrations and attained their final positions, and the border between layers 3 and 4 cannot be recognized histologically. Accordingly, ${ }^{3} \mathrm{H}$-thymidine was administered at E42, a time chosen in order to label the cells destined for the upper part of layer 4 and the deeper parts of layer 3 , and the resulting autoradiographic labeling pattern was examined at birth. The results of this experiment are shown in the dark-field autoradiograph of Figure $9 A$, where it can be seen that cells belonging to the layer $3 / 4$ border zone have already completed their migrations and assembled in a band close to the top of the cortical plate. The superficial position of this labeled band of cells is at first unexpected, because it implies that the top of layer 4 is very nearly at the pial surface at this age. In fact, by comparing the dark-field autoradiograph with an adjacent brightfield section counterstained with cresyl violet (Fig. 9B), it becomes clear that the zone of cell labeling is located superficially, and is only separated from layer 1 by a thin band of compact cells (Fig. 9B, asterisk), which reaffirms the point that the majority of the cells of cortical layer 4 are situated in the upper half of the cortical plate at birth. This finding also implies that many of the neurons belonging to the superficial cortical layers (layers 2 and 3 ) are still en route through the cortical plate to their final positions above layer 4 .

To examine this possibility, ${ }^{3} \mathrm{H}$-thymidine was administered at E48, a time when neurons destined exclusively for layers 2 and 3 are generated (Luskin and Shatz, 1985b), and the resulting labeling pattern was again examined at birth. The results of this 

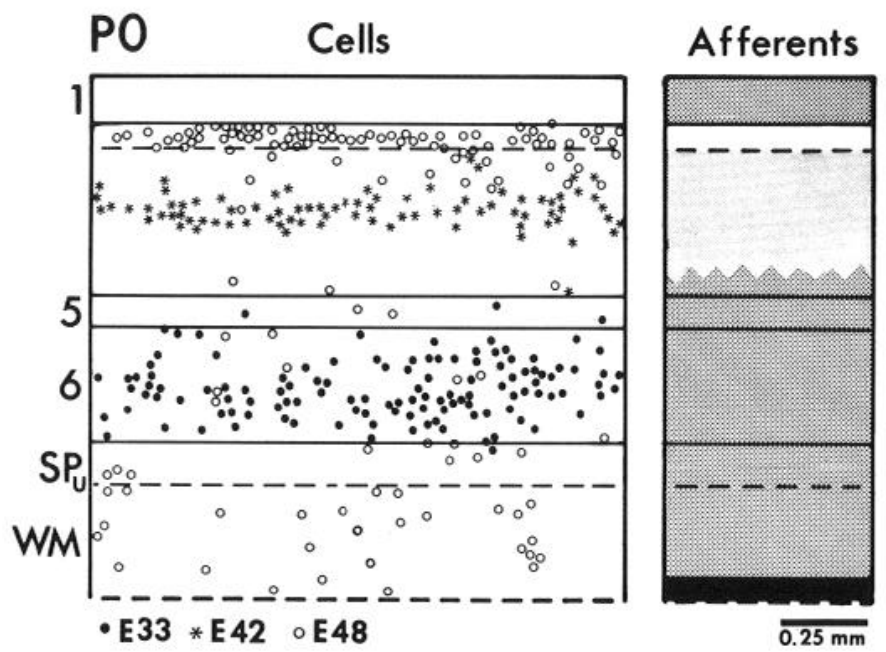

Figure 10. Camera lucida drawings summarizing the relationship at birth $(P 0)$ between the location of geniculocortical afferents in the primary visual cortex and the cells destined to belong to layer 6 , the upper part of layer 4, and the superficial cortical layers (layers 2 and 3). Lefthand panel illustrates superimposed drawings of the distribution of heavily labeled cells resulting from injections of ${ }^{3} \mathrm{H}$-thymidine at E33 (black dots) labeling the cells destined for layer 6, at E42 (asterisks) to label the cells destined for the layer 3/4 border, or at E48 (open circles) to label cells destined for the superficial cortical layers. Drawings on the right depict the pattern of transneuronally labeled geniculocortical afferents at birth (see Fig. 6). Geniculocortical afferents are present everywhere within the cortex except in the thin zone that contains cells destined for layers 2 and 3 . Note, however, that fewer afferents are present within the upper half of the cortical plate, where layer 4 cells are situated (asterisks) than within the deeper cortical layers.

experiment are shown in the dark-field autoradiograph of Figure $9 C$. A dense band of heavily labeled cells is present at the top of the cortical plate in a position corresponding to the thin band of compact cells seen in the cresyl violet-stained section of Figure $9 B$, indicating that some of the cells belonging to layers 2 and 3 have traversed layer 4 and assumed a more superficial position. However, significant numbers of cells destined for the superficial layers are still en route through the cortical plate, as can be seen by the autoradiographic labeling pattern in Figure $9 C$ (e.g., white arrows). This observation applies not only to the cells generated at E48, but also to the large contingent of layer 2 and 3 cells that continue to be generated until E57 (Luskin and Shatz, 1985b). For example, in an animal injected with ${ }^{3} \mathrm{H}-$ thymidine at E56 and examined at birth (not shown), labeled cells were found at all depths of the developing telencephalon, with the majority still migrating through the intermediate zone and only a small fraction present within the zone of compact cells of the cortical plate. Thus, the cortex at birth is extremely immature with regard to the formation of the superficial cortical layers.

With this analysis in hand, we can now consider the relationship between the position of the geniculocortical afferents and the neurons of layer 4 at birth. We again made camera lucida drawings of autoradiographs from ${ }^{3} \mathrm{H}$-thymidine and transneuronally labeled material and superimposed the results, as shown in Figure 10. Three separate sets of ${ }^{3} \mathrm{H}$-thymidine injections were made in order to identify the cells of layer 6 (injection at E33), the superficial half of layer 4 (E42), and layers 2 and 3 (E48). Comparison of the distributions of labeled cells with labeled afferents indicates that by birth, the geniculocortical afferents are found in association with all of their cortical target cells, with the most substantial projections to layers 6 and 1 , and a weaker projection to the regions of the superficial cortex containing the cells of layer 4 . The only part of the cortical plate not receiving geniculocortical input is the zone of compact cells just below layer 1 .

In view of our finding that the superficial half of the cortex is remarkably immature at birth with respect to the laminar arrangement of cells, we wished to determine when the cells of layer 4 come to assume their adultlike position in the middle of the cortical plate. Figures 11 and 12 show that this occurs by $\mathrm{P} 25$. At this age, each cortical layer can be identified on the basis of conventional histological criteria (LeVay and Gilbert, 1976; Otsuka and Hassler, 1962). For example, as shown in the cresyl violet-stained section of Figure 11 (P25), the layer 3/4 border is demarcated by large pyramidal cells, while the layer $4 / 5$ border is demarcated by the large pyramids of layer 5 . These criteria can be used to recognize the boundaries of layer 4 as early as P11 (Fig. 11), but at this early age, the continued presence of the zone of compact cells below layer 1 (not found at P25) signals that the superficial cortical layers are still immature. These impressions are reinforced by examining the cortical labeling patterns at $\mathrm{P} 11$ and $\mathrm{P} 25$ resulting from ${ }^{3} \mathrm{H}$-thymidine injections designed to label the cells belonging to upper layer 4 . As shown in the camera lucida drawings of Figure 12, the relative positions of the cells destined for the layer $3 / 4$ border are adultlike by P25 (cf. Fig. 12 of Luskin and Shatz, 1985b; see Fig. 12).

\section{Discussion}

In this study, we have used both the method of transneuronal transport of intraocularly injected ${ }^{3} \mathrm{H}$-proline and ${ }^{3} \mathrm{H}$-thymidine birthdating to examine the relationship between the geniculocortical projection and its major targets, the neurons of cortical layers 4 and 6 , during the prenatal development of the cat's visual system. The results show that axons from the LGN grow into the telencephalon very early during fetal development, before many of the cortical neurons that they eventually contact in layer 4 have even been generated at the ventricular zone. As a solution to the logistic problem created by this temporal disparity we have found that the ingrowing geniculocortical axons evidently do not grow immediately into the developing cortical plate when they first arrive within the vicinity of the future visual cortex. Rather, axons accumulate for several weeks below the cortical plate in a region of the intermediate zone known as the subplate. Only later do they invade their target cortical layers, after the neurons comprising those layers have completed their migrations and assumed their final relative positions within the cortex.

\section{Methodological considerations}

The conclusions of this study are based on interpretations of the autoradiographic labeling patterns resulting from ${ }^{3} \mathrm{H}$-thymidine administration, on the one hand, and transneuronal transport of ${ }^{3} \mathrm{H}$-proline on the other. Interpretation of the ${ }^{3} \mathrm{H}$ thymidine autoradiographs is relatively unambiguous, given the long duration and precision of cortical neurogenesis in the catat least 1 week is required to generate the cells of each cortical layer (Luskin and Shatz, 1985b)-compared to the fact that the ${ }^{3} \mathrm{H}$-thymidine that is administered by intrauterine injection is available only for uptake by cells undergoing DNA synthesis prior to division - for at most $4 \mathrm{hr}$ (Hickey et al., 1983). Consequently, it is possible to label a discrete population of cortical cells destined for a particular cortical location with an appropriately timed pulse of ${ }^{3} \mathrm{H}$-thymidine.

The situation regarding the interpretation of the transneuronally transported label is less secure for several reasons. The first relates to a problem associated with uniformity of uptake of ${ }^{3} \mathrm{H}$-proline within the fetal retina following an eye injection. In our experience, it is quite difficult to ensure uniform uptake of label, although this problem can be minimized to some extent by making 2 injections per eye, 1 in the temporal retina and 1 


\section{P11}

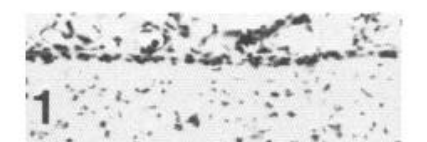

P25
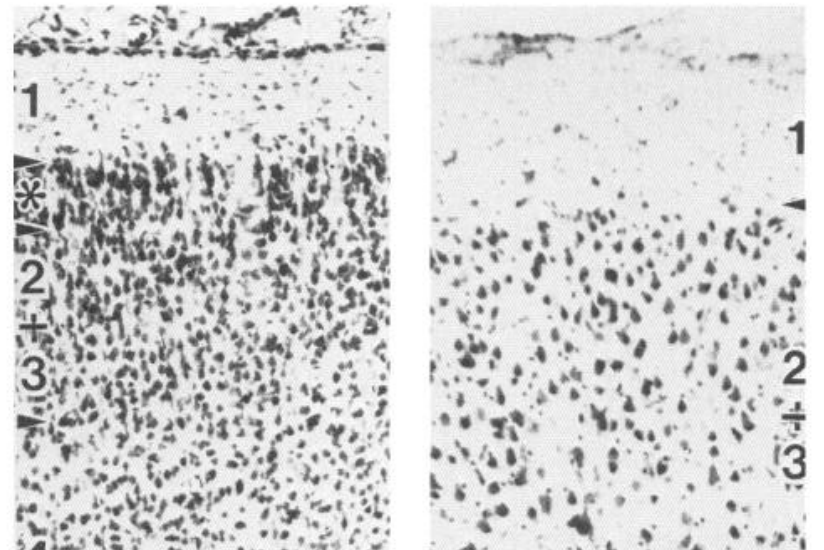

$4,4=040$
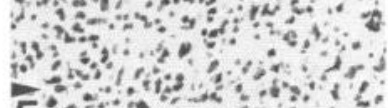

5
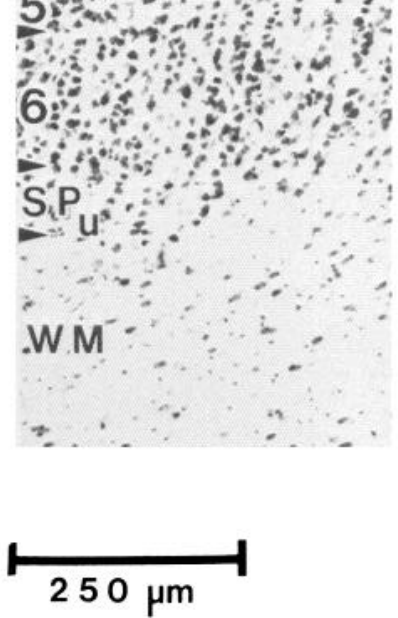

E43-P11

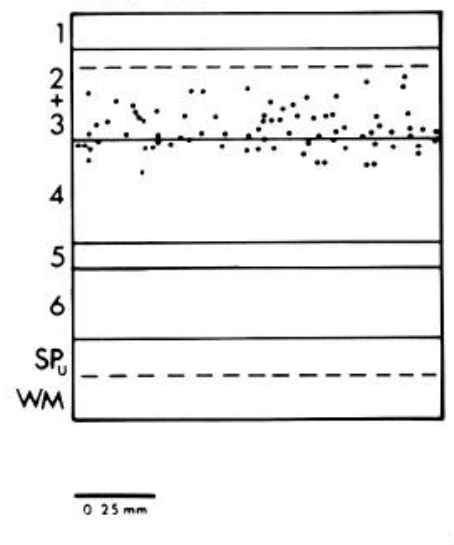

$\mathrm{E} 42-\mathrm{P} 25$

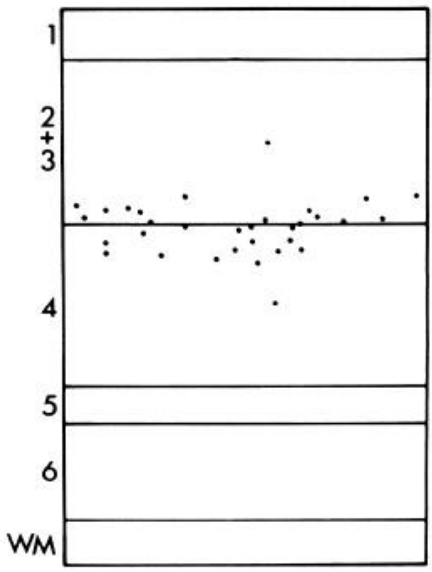

Figure 12. Camera lucida drawings showing the distribution of heavily labeled neurons (black dots) destined for the layer 3/4 border at P11 (left) or P25 (right), resulting from a ${ }^{3} \mathrm{H}$-thymidine injection on $\mathrm{E} 42$ or E43. At P25, the relative position of labeled cells within the cortex is adultlike, whereas at $P 11$, the labeled cells are situated very close to the pial surface. Dashed line below layer 1 at P11 delineates zone of compact cells (see Fig. 11).

particular experiment demonstrate that the connections between LGN and cortex are in rough topographic order by birth.

Another problem involves distinguishing transneuronally transported label from general background label, which, in fetal animals, is higher than that found postnatally (cf. LeVay et al., 1978). For instance, in most of the cases illustrated, high levels of labeling can be seen in the pia and near the ventricular surface (see especially Figs. 2 and 3). This label is almost certainly due to the nonspecific uptake of radioactivity released following specific transport to the LGN, or made directly available from the eye injection. In general, nonspecific labeling does not affect our conclusions concerning the pattern of transneuronal labeling seen following an eye injection, but it does affect any conclusions concerning the precise timing of development of the geniculocortical pathway. Consequently, the results reported here should be considered upper time limits. It is possible that geniculocortical axons arrive within the subplate even prior to E42 and invade the cortical plate earlier than E55, but cannot be detected with the autoradiographic methods used in this study. Even so, it is worth stressing that, by E55, significant levels of transneuronally transported label are not found within the cortical plate compared to the subplate, which suggests that, in fact, substantial numbers of geniculocortical axons do not invade the cortical plate until close to this age. Experiments designed to directly fill individual geniculocortical axons with HRP are currently in progress and should provide additional information on the timing of development of this projection.

\section{Development of cellular lamination}

At birth, the cat's visual cortex is remarkably immature in several important respects. For instance, the results of our ${ }^{3} \mathrm{H}-$ thymidine-labeling experiments show that the majority of cells belonging to the superficial cortical layers have not yet assumed their adult laminar positions, but rather are still migrating through the white matter and the deeper cortical layers. As a consequence, adultlike cortical lamination is not present at birth, and it is not possible simply to assign cortical layers by assuming that the upper half of the cortical plate can be subdivided into cortical layers 1,2 , and 3 . On the contrary, we have shown here that at this age the upper half of the cortical plate consists primarily of the postmigratory cells of layer 4 , while future layers

2 and 3 are represented only by a thin band of compact cells tion. Despite this limitation, however, there is no question that, by birth, significant numbers of geniculocortical afferents have invaded cortical layers 4 and 6 . Moreover, the results from this 
inserted betwecn the cells of laycr 4 and the marginal zone (see Figs. 9 and 10).

Several lines of evidence suggest that the majority of cells destined for the superficial cortical layers complete their migrations and assume their final laminar locations by about 3 weeks postnatal. The first is based on an estimate of the time required to migrate the full distance outwards from the ventricular zone. In the cat, as in primates (Rakic, 1975), this time increases as development proceeds, in part because of the increase in thickness of the telencephalon itself. For instance, results from our previous ${ }^{3} \mathrm{H}$-thymidine studies of cat visual cortex (Luskin and Shatz, 1985a) have indicated that about a week is needed for the majority of neurons of cortical layer 6 to complete their migrations. From results reported here, we can estimate that, for the neurons of cortical layer 4 , about 2 weeks are required (e.g., neurons destined for the layer $3 / 4$ border are generated at E43 and are only seen near the pial surface in large numbers by E57; see Figs. 7 and 8). Consequently, it is very likely that even more than 2 weeks are required for neurons born at E57-the last day of visual cortical neurogenesis (Luskin and Shatz, 1985b) - to complete their migrations, a possibility supported by the present finding that the majority of cells labeled from an injection of ${ }^{3} \mathrm{H}$-thymidine at $\mathrm{E} 56$ have not yet reached the top of the cortical plate by birth.

A second line of evidence comes from the observation that even 2 weeks after birth, a thin band of compact cells is present immediately below the marginal zone (Fig. 11). Results from the ${ }^{3} \mathrm{H}$-thymidine-labeling experiments presented here (Figs. 7, 9) indicate that throughout development this compact band contains newly arrived, postmigratory neurons that presumably have not yet differentiated sufficiently to create a surrounding neuropil. Accordingly, the disappearance of this band of compact cells should signal completion of the major phase of cell migration and the onset of differentiation of the most superficial neurons of the primary visual cortex. We have found that this band is gone by 3 postnatal weeks (Fig. 11), further support for the conclusion that cell migration in the cat's visual cortex has ceased sometime between 2 and 3 weeks after birth.

The ${ }^{3} \mathrm{H}$-thymidine-labeling experiments also permit us to estimate when the majority of neurons destined for the deeper cortical layers $(4,5$, and 6$)$ complete their migrations. Results indicate that the last-generated neurons of layer 6 assume their final position within the cortical plate early in fetal life-by about E40-while the migration of cells destined for layer 4 is complete by about E57. Consequently, by birth the migration of cells destined for the deeper cortical layers is virtually complete, and differentiation is also well under way, making histological identification, particularly of layers 5 and 6 , quite feasible.

These considerations indicate that the conclusions drawn from previous physiological and anatomical studies of the visual cortex of the neonatal kitten may require reinterpretation. For instance, up until about 2 postnatal weeks, physiological recordings from the superficial half of the visual cortex have most likely been made from cells belonging to layer 4 and the deeper part of layer 3 (cf. Albus and Wolf, 1984; Hubel and Wiesel, 1963; LeVay et al., 1978), since the neurons of upper layer 3 and layer 2 have not yet completed their migrations. Similarly, the arbitrary subdivision of the superficial half of the neonatal kitten visual cortex into conventional laminae in anatomical studies has led to the incorrect suggestion that cortical layers 2 and 3 receive a significant input from the LGN (see Kato et al., 1983, and 1984, Figs. 1 and 2, and LeVay et al., 1978, Fig. 9). Furthermore, the interpretation of a recent study of the redistribution of muscarinic receptor binding sites during postnatal development of kitten visual cortex (Shaw et al., 1985) is also questionable, since the observed redistribution can be explained by our finding that, at birth, the top of layer 4 extends practically to the marginal zone. Finally, caution is also required in the interpretation of the laminar pattern of retrogradely labeled association and callosal cortical neurons in neonatal cat visual cortex following injections of other cortical areas (Price and Blakemore, 1985). In the adult, of course, these neurons are principally located in the supcrficial cortical layers (2 and 3 ), but, as we have shown here, many of these neurons are still migrating through the deeper cortical layers during the first 2 weeks postnatal. Since migrating neurons may elaborate axonal projections (Levi-Montalcini, 1950; Morest, 1970; Nowakowski and Rakic, 1979; Shatz and Rakic, 1981; Shoukimas and Hinds, 1978), it is not possible to draw reliable conclusions about the laminar origin of retrogradely labeled cells until migration of superficial cortical layers is complete at around 2 weeks after birth.

\section{Development of the geniculocortical projection}

The visual cortex of the neonatal kitten is not only immature as regards cellular lamination, but also with respect to the arrangement of the geniculocortical afferents. In a previous study of the postnatal development of the geniculocortical projection in the cat, LeVay et al. (1978) found that afferents from the LGN are present within layer 4 by P8, the earliest time that could be studied using the transneuronal transport method without necessitating fetal surgery. The results of our experiments using similar methods in utero are perfectly consistent with these previous findings, since we have shown that, at birth, afferents from the LGN can also be detected in appreciable numbers within the region of the cortex destined to become layer 4 in the adult. However, even during the brief 1 week period between birth and $8 \mathrm{~d}$, the relative pattern of transneuronal labeling changes, so that the zone of heaviest labeling shifts from layers 5 and 6 at birth to layer 4 at $8 \mathrm{~d}$. We interpret this shift in labeling as indicating that a major component of the geniculocortical projection has left the subplate and deeper cortical layers and grown into layer 4 by $8 \mathrm{~d}$ after birth.

Another indication of the immaturity of the geniculocortical projection at birth is the presence of significant amounts of transneuronally transported label just below the pial surface in layer 1 . While it is known that in the adult layer 1 receives input from the C-layers of the LGN (Ferster and LeVay, 1978; LeVay and Gilbert, 1976; Leventhal, 1979), the projection is so sparse that it cannot be clearly labeled by the method of transneuronal autoradiography (instead, direct LGN injections are required). In contrast, LeVay et al. (1978) reported that in 1-3-week-old kittens the transneuronal transport method resulted in heavy labeling of the geniculocortical projection to layer 1, and recent experiments (Kato et al., 1984) have demonstrated that in neonatal kittens this projection arises primarily from the LGN $\mathrm{C}$-layers as well. The results of our study confirm and extend these observations, since the projection to layer 1 can be detected in our material prenatally, as early as E46. It would be of interest to know whether this early projection is again supplied by some of the neurons destined to belong to the C-layers. If so, this possibility might account for the repeated observation that the ventral regions of the C-layers (nearest the optic tract) contain remarkably large and well-differentiated neurons even at early fetal ages (Card-Linden et al., 1981; Shatz, 1983; Shotwell et al., 1986).

Despite the fact that a substantial geniculocortical projection to layer 4 is present by 1 week after birth in the cat, it is not until 3 weeks postnatal that the afferents begin to segregate from one other according to eye preference to form the system of ocular dominance columns in layer 4 (LeVay et al., 1978). The results of the present study provide one explanation for this delay. As mentioned above, it is not until about 3 weeks after birth that the majority of cortical neurons destined for the superficial layers traverse layer 4 and complete their migrations. 
Although detailed information is lacking, it appears that a similar sequence of events characterizes development of the primate visual system (Rakic, 1974, 1975, 1977). These considerations suggest a general developmental rule: that the process of afferent segregation, wherever it occurs, requires that all neuronal migration has ceased.

\section{Relation between geniculocortical afferents and their cortical targets during development}

A major finding of this study is that there is a delay of about 3 weeks between the time when geniculocortical afferents first arrive within the white matter below the vicinity of the visual cortex (at E42) and the time when axons can first be detected within future cortical layer 4 (at P0) (see Fig. 6). Delays in the ingrowth of geniculocortical afferents have also been noted in the development of the primate (Rakic, 1977) and rodent (Lund and Mustari, 1977) visual systems, though, in these cases, the duration of the delay has not been determined with accuracy for various reasons. For example, in the primate the experiments have not been performed early enough to determine when axons first arrive below the region of the cortical plate destined to become primary visual cortex; in the rodent, the development of the geniculocortical projection was examined by means of anterograde degeneration following LGN lesions-a method that we believe is even more unreliable than transneuronal autoradiography for detecting the presence of very early projections. Nevertheless, the results from studies of all 3 species indicate that a general feature of the development of the geniculocortical projection is that there is a delay in the ingrowth of axons into the cortical plate. Moreover, such delays are likely to be typical of the development of thalamocortical connections in general, in view of the fact that connections between somatosensory thalamus and cortex behave in a similar fashion (Killackey and Belford, 1979; Wise and Jones, 1978; Wise et al., 1977).

These observations have given rise to the concept of a "waiting period" (Lund and Mustari, 1977; Rakic, 1977) during which the majority of geniculocortical axons appear to accumulate immediately beneath the cortical plate in a region called the "subplate" (discussed further below). This prompts us to ask how the timing and duration of waiting and ingrowth of the geniculocortical axons are related to the periods of neuronal migration and formation of cortical layers 4 and 6 . As mentioned above, the results of our ${ }^{3} \mathrm{H}$-thymidine studies have shown that the neurons of layer 6 are in position within the cortical plate relatively early-around E40; yet we have demonstrated that the first geniculocortical afferents cannot be detected within layer 6 until about E55. For layer 4, the last generated neurons are postmigratory by about E57, while the afferents can only be detected by E65. Thus, for both layers 4 and 6 , there is likely to be a similar waiting period of 1 to 2 weeks between the completion of neuronal migration and the ingrowth of the geniculocortical afferents.

Even though the geniculocortical afferents are situated in the direct pathway along which the neurons of layers 4 and $6 \mathrm{mi}-$ grate, they fail to promptly follow their ultimate targets up into the cortical plate in numbers sufficient to permit detection by means of transneuronal autoradiography. Rather, in each instance many afferents wait until after their target cells have completed their migrations. This observation raises a number of questions concerning the nature of the waiting period and the ultimate signal for ingrowth into the cortical plate. In the case of layer 4 , a waiting period of some sort might be expected simply in view of the fact that many axons from the LGN arrive within the vicinity of the visual cortex by E40, a time when the majority of neurons destined for the upper half of layer 4 have not yet even been generated at the ventricular zone (Luskin and Shat $z, 1985$ b). Regarding layer 6, however, the situation is not quite as straightforward, since by E40 the majority of neurons belonging to layer 6 are postmigratory and occupy their final positions. Nevertheless, afferents cannot be detected until E55. These considerations suggest that factors other than simple proximity must play an important role in determining the timing of afferent ingrowth into the cortical plate. For instance, one such factor might be that a certain level of maturity within the target populations in layers 4 and 6 is required.

Similar considerations might apply to cortical development as a whole. Thus, whenever a waiting period exists, a temporal mismatch might be expected between the time of arrival of the afferent system under study and the time when target cortical neurons achieve sufficient postmigratory maturity. The development of callosal connections is likely to prove another good case in point. Recent studies have shown that the majority of callosal axons also initially accumulate below the cortical plate (Innocenti, 1981; Wise and Jones, 1976, 1978). In view of our own results, we would not expect to find large numbers of callosal axons in the superficial half of the cortical plate until after the appropriate targets in layers 2 and 3 complete their migrations; that is, until around 2 weeks after birth in the cat.

It is important to consider not only the maturity of cortical neurons, but also the nature of the environment in which the afferents "wait." As mentioned previously, the afferents accumulate in a region of the intermediate zone (future white matter), sandwiched between the optic radiations and the base of layer 6, known as the subplate (Boulder Committee, 1970; Luskin and Shatz, 1985a; Rakic, 1982). During development, this zone contains not only the ingrowing afferent systems (thalamocortical, corticocortical, callosal) and neurons migrating en route to the cortical plate, but also a special type of cell, the subplate cell (Luskin and Shatz, 1985a; Kostovic and Rakic, 1980). Recently we (Chun et al., 1985, 1986) have found that the subplate cells are almost certainly neurons that reach a high degree of morphological and ultrastructural maturity during prenatal life. In contrast to the neurons of the cortical plate, however, the majority of subplate cells do not persist into adulthood, but, instead, disappear, according to Golgi and ${ }^{3} \mathrm{H}$-thymidine studies (Bradford et al., 1977; Kostovic and Rakic, 1980; Luskin and Shatz, 1985a). Thus, the growth of geniculocortical afferents into the cortical plate may be controlled by a delicate balance of many factors, including the maturation of the neurons of cortical layers 4 and 6 and the maturation and subsequent disappearance of the special neurons of the subplate zone.

\section{References}

Albus, K., and W. Wolf (1984) Early postnatal development of neuronal function in the kitten's visual cortex: A laminar analysis. J. Physiol. (Lond.) 348: 153-185.

Boulder Committee (1970) Embryonic vertebrate central nervous system: Revised terminology. Anat. Rec. 166: 257-261.

Bradford, R., J. G. Parnavelas, and A. R. Lieberman (1977) Neurons in layer 1 of the developing occipital cortex of the rat. J. Comp. Neurol. 176: 121-132.

Card-Linden, D., R. W. Guillery, and J. Cucchiaro (1981) The dorsal lateral geniculate nucleus of the normal ferret and its postnatal development. J. Comp. Neurol. 203: 189-211.

Chun, J. J. M., M. K. Nakamura, and C. J. Shatz (1985) Transient neurons immunoreactive for peptides in fetal cat's telencephalon. Soc. Neurosci. Abstr. 11: 808.

Chun, J. J. M., M. K. Nakamura, and C. J. Shatz (1986) Transient cells of the developing mammalian telencephalon are peptide-immunoreactive neurons. Nature (in press).

Ferster, D., and S. LeVay (1978) The axonal arborization of lateral geniculate neurons in the striate cortex of the cat. J. Comp. Neurol. 182: 923-944.

Hickey, T. I., and P. F. Hitchcock (1984) Genesis of neurons in the dorsal lateral geniculate nucleus of the cat. J. Comp. Neurol. 228: 186-199.

Hickey, T. L., D. R. Whikehart, C. A. Jackson, P. F. Hitchcock, and J. D. Peduzzi (1983) Tritiated thymidine experiments in the cat: A 
description of techniques and experiments to define the time-course of radioactive thymidine availability. J. Neurosci. Methods $8: 139$ 147.

Hubel, D. H., and T. N. Wiesel (1963) Receptive fields of cells in striate cortex of very young, visually inexperienced kittens. J. Neurophysiol. 26: 994-1002.

Innocenti, G. M. (1981) Growth and reshaping of axons in the establishment of visual callosal connections. Science 212: 824-827.

Kato, N., S. Kawaguchi, T. Yamamoto, A. Samejima, and H. Migata (1983) Postnatal development of the geniculocortical projection in the cat: Electrophysiological and morphological studies. Exp. Brain Res. 51: 65-72.

Kato, N., S. Kawaguchi, and H. Miyata (1984) Geniculocortical projection to layer 1 of area 17 in kittens: Orthograde and retrograde HRP studies. J. Comp. Neurol. 225: 441-447.

Killackey, H. P., and G. R. Belford (1979) The formation of afferent patterns in the somatosensory cortex of the neonatal rat. J. Comp. Neurol. 183: 285-304.

Kostovic, I., and P. Rakic (1980) Cytology and time of origin of interstitial neurons in the white matter in infant and adult human and monkey telencephalon. J. Neurocytol. 9: 219-242.

LeVay, S., and C. D. Gilbert (1976) Laminar patterns of geniculocortical projection in the cat. Brain Res. 113: 1-19.

LeVay, S., M. P. Stryker, and C. J. Shatz (1978) Ocular dominance columns and their development in layer IV of the cat's visual cortex: A quantitative study. J. Comp. Neurol. 179: 223-244.

Leventhal, A. G. (1979) Evidence that the different classes of cells of the cat's lateral geniculate nucleus terminate in different layers of the striate cortex. Exp. Brain Res. 37: 349-372.

Levi-Montalcini, R. (1950) The origin and development of the visceral system in the spinal cord of the chick embryo. J. Morphol. 86: 253284.

Lund, R. D., and M. J. Mustari (1977) Development of the geniculocortical pathway in rats. J. Comp. Neurol. 173: 289-306.

Luskin, M. B., and C. J. Shatz (1984) Spatio-temporal relations between the cells of layers 4 and 6 and their geniculocortical afferent input during development. Soc. Neurosci. Abstr. 10: 1079.

Luskin, M. B., and C. J. Shatz (1985a) Cogeneration of subplate and marginal zone cells in the cat's primary visual cortex. J. Neurosci. 5: 1062-1075.

Luskin, M. B., and C. J. Shatz (1985b) Neurogenesis of the cat's primary visual cortex. J. Comp. Neurol. 242: 611-631.

Morest, D. K. (1970) The pattern of neurogenesis in the retina of the rat. Z. Anat. Entwickl. Ges. 131: 45-67.

Nowakowski, R. S., and P. Rakic (1979) The mode of migration of neurons to the hippocampus: A Golgi and electron microscopic analysis in foetal rhesus monkey. J. Neurocytol. 8: 697-718.

Otsuka, R., and R. Hassler (1962) Über Aufbau und Gliederung der corticalen Sehsphare bei der Katze. Arch. Psychiatr. Z. Neurol. 203 : 212-234.
Price, D. J., and C. Blakemore (1985) The postnatal development of the association projection from visual cortical area 17 to area 18 in the cat. J. Neurosci. 5: 2443-2452.

Rakic, P. (1974) Neurons in rhesus monkey visual cortex: Systematic relation between time of origin and eventual disposition. Science 183: 425-427.

Rakic, P. (1975) The timing of major ontogenetic events in the visual cortex of the rhesus monkey. In Brain Mechanisms in Mental Retardation, N. A. Buchwald and M. Brazier, eds., pp. 3-40, Academic, New York.

Rakic, P. (1977) Prenatal development of the visual system in rhesus monkey. Phil. Trans. R. Soc. Lond. [Biol.] 278: 245-260.

Rakic, P. (1982) Early developmental events: Cell lineages, acquisition of neuronal positions and areal laminar development. In Development and Modifiahility of the Cerehral Cortex, P. Rakic and P. S. GoldmanRakic, eds., p. 440, M.I.T. Press, Cambridge, MA.

Shatz, C. J. (1981) Inside-out pattern of neurogenesis of the cat's lateral geniculate nucleus. Soc. Neurosci. $\Lambda$ bstr. 6: 485.

Shatz, C. J. (1983) The prenatal development of the cat's retinogeniculate pathway. J. Neurosci. 3: 482-499.

Shatz, C. J., and P. Rakic (1981) The genesis of efferent connections from the visual cortex of the fetal rhesus monkey. J. Comp. Neurol. 196: 287-307.

Shatz, C. J., S. H. Lindstrom, and T. N. Wiesel (1977) The distribution of afferents representing the right and left eyes in the cat's visual cortex. Brain Res. 131: 103-110.

Shaw, C., M. C. Needler, M. Wilkinson, C. Aoki, and M. Cynader (1984) Modification of neurotransmitter receptor sensitivity in cat visual cortex during the critical period. Dev. Brain Res. 22: 67-73.

Shotwell, S. L., C. J. Shatz, and M. B. Luskin (1986) Development of glutamic acid decarboxylase immunoreactivity in the cat's lateral geniculate nucleus. J. Neurosci. 6: 1410-1423.

Shoukimas, G. M., and J. W. Hinds (1978) The development of the cerebral cortex in the embryonic mouse: An electron microscope serial section analysis. J. Comp. Neurol. 179: 795-830.

Wiesel, T. N., D. H. Hubel, and D. M. K. Lam (1974) Autoradiographic demonstration of ocular-dominance columns in the monkey striate cortex by means of transneuronal transport. Brain Kes. 79: 273-279.

Wise, S. P., and E. G. Jones (1976) The organization and postnatal development of the commissural projection of the rat somatic sensory cortex. J. Comp. Neurol. 168: 313-344.

Wise, S. P., and E. G. Jones (1978) Developmental studies of thalamocortical and commissural connections in the rat somatic sensory cortex. J. Comp. Neurol. 175: 187-208.

Wise, S. P., S. H. C. Hendry, and E. G. Jones (1977) Prenatal development of sensorimotor cortical projections in cats. Brain Res. 138: 538-544. 